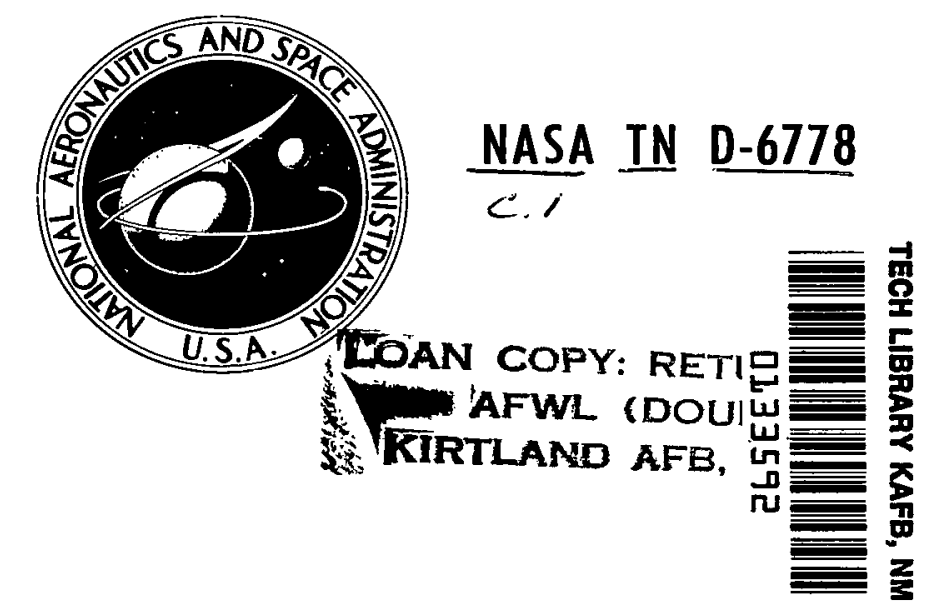

\title{
EVALUATION OF BORON-EPOXY-REINFORCED
}

\section{TITANIUM TUBULAR TRUSS FOR APPLICATION}

TO A SPACE SHUTTLE BOOSTER

\section{THRUST STRUCTURE}

by Nicholas Corvelli and Robert Carri

Langley Research Center

Hampton, Va. 23365

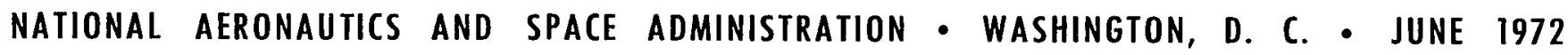




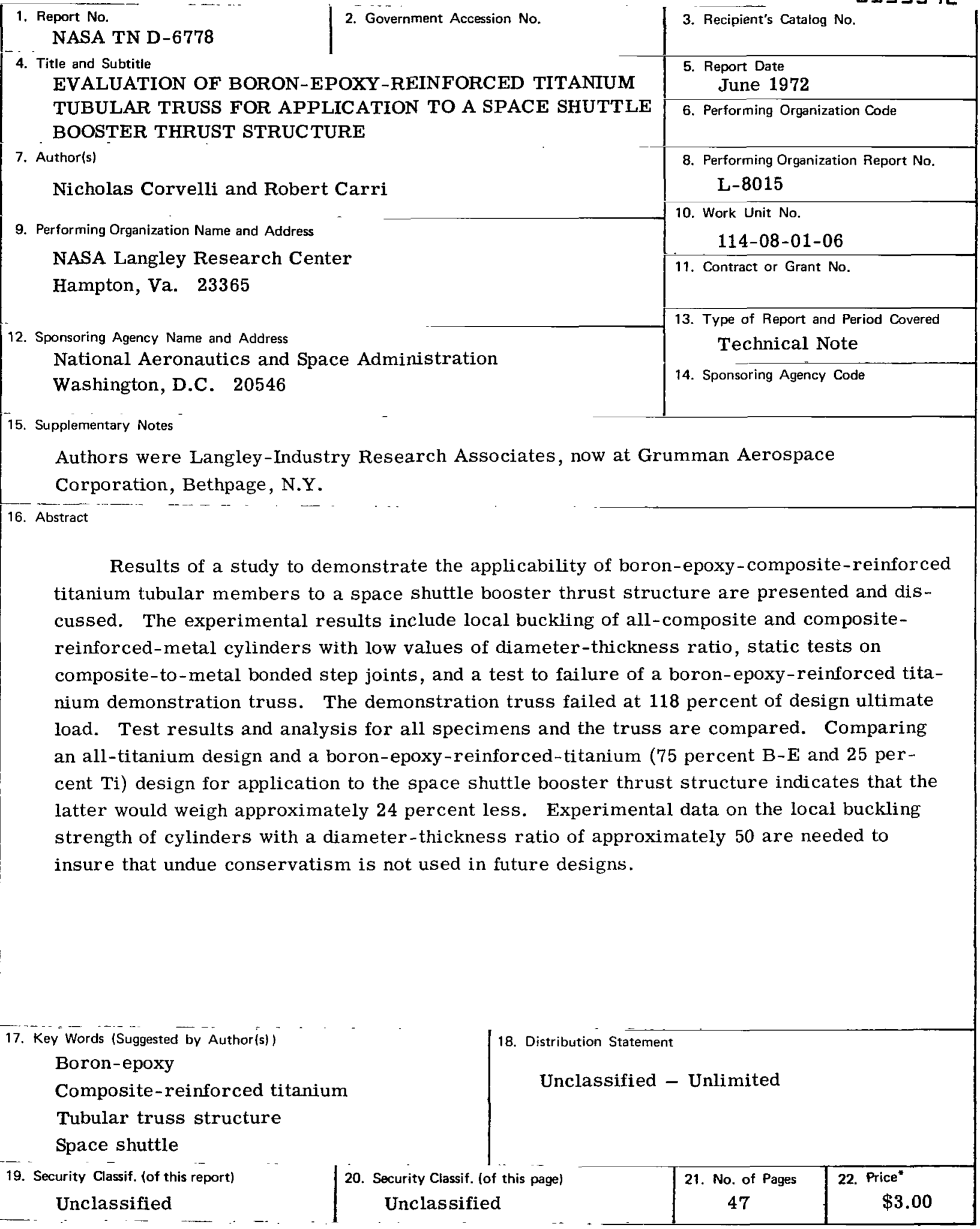

*For sale by the National Technical Information Service, Springfield, Virginia 22151 


\title{
EVALUATION OF BORON-EPOXY-REINFORCED TITANIUM
}

\section{TUBULAR TRUSS FOR APPLICATION TO A SPACE}

\section{SHUTTLE BOOSTER THRUST STRUCTURE}

\author{
By Nicholas Corvelli* and Robert Carri ${ }^{*}$ \\ Langley Research Center
}

\section{SUMMARY}

Results of a study to demonstrate the applicability of boron-epoxy-compositereinforced titanium tubular members to a space shuttle booster thrust structure are presented and discussed. The experimental results include local buckling of all-composite and composite-reinforced-metal cylinders with low values of diameter-thickness ratio, static tests on composite-to-metal bonded step joints, and a test to failure of a boronepoxy-reinforced titanium demonstration truss. The demonstration truss failed at 118 percent of design ultimate load. Test results and analysis for all specimens and the truss are compared. Comparing an all-titanium design and a boron-epoxy-reinforcedtitanium ( 75 percent B-E and 25 percent $\mathrm{Ti}$ ) design for application to the space shuttle booster thrust structure indicates that the latter would weigh approximately 24 percent less. Experimental data on the local buckling strength of cylinders with a diameterthickness ratio of approximately 50 are needed to insure that undue conservatism is not used in future designs.

\section{INTRODUCTION}

The demand for increased structural efficiency in aerospace vehicles can be met by the use of relatively expensive, advanced composite materials. At the same time, the rising cost of aerospace vehicles dictates that composite materials be utilized in the most effective manner. One approach which appears to offer the potential of meeting this goal is a composite-reinforced-metal concept reported in reference 1. In reference 1, it was shown that the structural efficiency of a metal tube loaded in axial compression can be increased substantially by bonding composite material to the exterior surface of the tube. The weight savings obtainable through increased structural efficiency and the unit costs of that weight savings are dependent upon the amount of composite material used. In the

\footnotetext{
*Langley-Industry Research Associate, now at Grumman Aerospace Corporation, Bethpage, N.Y.
} 
design, the percentage of composite reinforcement utilized would depend upon the acceptable unit cost of any weight savings for the particular vehicle application. In the study reported herein, a segment of a $1 / 3$-scale thrust structure which included two boronepoxy-reinforced titanium tubular members and a lightweight titanium joint cluster was designed and tested. The results were extrapolated to predict the weight savings of a boron-epoxy-reinforced titanium truss compared with that of an all-titanium design.

The research effort was performed by Grumman Aerospace Corporation engineers assigned to the Langley Research Center under the Langley-Grumman Research Associate Program. Overall program guidance, hardware manufacture, and test support were provided by Langley Research Center personnel.

\section{SYMBOLS}

The units for the physical quantities defined in this paper are given both in the International System of Units (SI) and the U.S. Customary Units. The measurements and calculations were made in U.S. Customary Units. Conversion factors relating the two systems are given in reference 2 , and those pertinent to the present investigation are presented in appendix A.

A column cross-sectional area, meters ${ }^{2}$ (inches 2 )

D mean diameter of tube, meters (inches)

E Young's modulus, newtons $/$ meter $^{2}$ (pounds force/inch2)

$\mathrm{G}_{\mathrm{LT}} \quad$ shear modulus in the longitudinal-transverse plane, newtons/meter 2 (pounds force/inch ${ }^{2}$ )

K factor defined by equation (C4)

L column length, meters (inches)

M moment in column, newton-meters (pound force-inches)

$\mathrm{M}_{1}, \mathrm{M}_{2} \quad$ end moments on column, newton-meters (pound force-inches)

P axial load, newtons (pounds force)

$\mathbf{r}$ mean radius of tube, meters (inches) 
tube wall thickness or layer thickness, meters (inches)

$\alpha$

filament orientation angle, measured from axis of tube, radians (degrees)

$\beta \quad$ stress ratio defined by equation (C8)

$\gamma \quad$ theory-experiment correlation factor (see eq. (C3))

$\nu_{\mathrm{LT}}, \nu_{\mathrm{TL}}$ major Poisson's ratio and minor Poisson's ratio, respectively

$\sigma \quad$ axial stress, $\mathbf{P} / \mathrm{A}$, newtons $/$ meter $^{2}$ (pounds force/inch ${ }^{2}$ )

$\sigma_{c} \quad$ critical column buckling stress, newtons $/$ meter $^{2}$ (pounds force/inch ${ }^{2}$ )

$\sigma_{\text {col }} \quad$ optimum column stress, newtons $/$ meter $^{2}$ (pounds force/inch ${ }^{2}$ )

$\sigma_{\mathrm{cr}} \quad$ critical local buckling stress, newtons $/$ meter $^{2}$ (pounds force/inch ${ }^{2}$ )

$\sigma_{\mathrm{e}} \quad$ Euler buckling stress, newtons/meter ${ }^{2}$ (pounds force/inch ${ }^{2}$ )

$\phi \quad$ factor defined by equation (C5)

Subscripts:

cal calculated

exp experimental

L longitudinal direction of laminate or lamina

$\max \quad \operatorname{maximum}$

$\mathrm{T} \quad$ transverse direction of laminate or lamina

SPACE SHUTTLE BOOSTER THRUST STRUCTURE

A model of the space shuttle booster thrust structure selected for use in this study and the location of the structure in the launch vehicle are illustrated in figure 1. The truss configuration had been chosen by the Marshall Space Flight Center for use in an earlier cost-weight study. The truss is built up from a series of planar sections and is 
approximately $11 \mathrm{~m}$ (36 ft) in diameter and $3 \mathrm{~m}(10 \mathrm{ft})$ deep. Loads from the nine engines are applied at the intersections at the bottom of the truss and transmitted through the members to the eight fuselage reaction points located around the circumference at the top of the structure. Two truss members and a connecting joint, labeled 'Demonstration Truss Components" in figure 1, were selected for detailed design and analysis. In order to limit cost and facilitate fabrication and test, it was decided that the demonstration truss would be a $1 / 3$-scale model.

The structural efficiency of a truss such as that shown in figure 1 is strongly dependent upon the designs of the joint clusters. Two types of connectors, tubular intersection and lug, were considered for the present study. The tubular-intersection connector provides a rigid end connection that is capable of reacting moments. However, final assembly of a three-dimensional truss with this type of connector for each member could be difficult to accomplish since all members would have to be slipped over the connectors. Alternatively, a lug design offers the more promise for a machined part fitting and for facilitating assembly. A joint cluster utilizing this type of connector could not, however, have all load lines intersecting at a common point since it would be unstable for an applied moment to the fitting. A combination of the two joining concepts, shown in figure 2, appears to offer the most potential for fabrication and assembly of the full-size three-dimensional truss. Accordingly, the joint cluster for the demonstration truss was designed with a lug fitting for the tension member and a tubular connection to the compression member.

A 1/3-scale model of the vertical planar truss which contains the demonstration truss components is shown in figure 3 , together with the primary internal load distributions for the engines in the symmetric and gimbaled configurations. To account for scaIing, the loads given in figure 3 are $1 / 3$ those for the full-scale truss.

\section{DESIGN AND ANALYSIS}

The basic tubular members of the demonstration truss were designed for ultimate load, defined as 1.5 times limit load, with a zero or slightly positive margin of safety. The tubular members were designed with approximately 75 percent boron-epoxy and 25 percent titanium by volume. Selection of this volume ratio was based on the costweight analysis presented in appendix $B$, which indicates that a further increase in volume of composite would result in a minimal additional weight reduction. In addition, it was anticipated that this high ratio of composite to metal would exhibit the potential problem areas associated with this design concept. Fittings and joints, both bolted and bonded, were designed for a margin of safety of 15 percent at ultimate load. No yielding was permitted at 1.15 times limit load. Material allowables for the boron-epoxy and titanium alloys are included in tables I and II, respectively. 
The geometrical parameters of the tubular compression member were obtained from the optimization analysis discussed in appendix $C$. The member was analyzed as a beam column with applied axial load and end moments. The geometric proportions of the compression member were optimized such that the resulting minimum-weight tube was critical in local buckling. The cylinder wall was assumed to be composed of a homogeneous orthotropic material for the local buckling analysis (ref. 3). After transforming the homogeneous design into one with discrete layers, the margin of safety was determined by using the local buckling analysis of reference 4 which includes the effects of the inhomogeneity of the orthotropic laminated tube wall. In cases where the analysis of reference 4 showed a negative margin of safety, arbitrary modifications were made to satisfy strength criteria. For both calculations, a correlation factor was included as a reduction of the theoretical buckling stress. Due to the high stiffness and strength of the boron-epoxy composite, optimized compression tubes have a configuration with low values of the diameter-thickness ratio $\mathrm{D} / \mathrm{t}$. For this study the ratio was approximately 50 . This range is not of practical interest for metallic tube design and, as a result, cylinder buckling test data in this range are deficient. In reference 5 , a curve of the correlation factor as a function of $\mathrm{r} / \mathrm{t}$ extrapolated into the region of interest indicates a correlation factor of 0.79 . Due to the scarcity of available test data in the region of interest for this application, a value for the correlation factor was based upon the results of cylinder tests performed in this program and presented in appendix D. A value of 0.6 was used.

Tension members were designed for ultimate strength based on the allowables presented in tables I and II. Failure of the member was assumed to occur when the allowable stress of the axial plies was obtained.

The stepped bonded joints for the tension and compression members were designed by using an analysis presented in reference 6 . This analysis neglects the tension stresses in the adhesive; however, it should be adequate for symmetric bonded joints where bending is negligible. For the tubular members, although the bonded joints are unsymmetric, the adhesive tension stresses are neglected and all out-of-plane bending is assumed to be balanced by hoop loads. In addition, the effect of the adhesive layers between the metal shims is neglected. The titanium joint cluster was designed as a lightweight structural component. The tubular connection was sized to mate with the compression member and the lug was designed by using the method described in reference 7.

\section{TEST SPECIMENS}

\section{Demonstration Truss}

The demonstration truss shown in figure 4 includes a 104-cm (41-in.) compression member, a 64-cm (25-in.) tension member, and a joint cluster machined from Ti-6Al-4V annealed. To facilitate loading, the demonstration truss was rotated so that the resultant 
applied load was vertical. The angle between the compression and tension members of the demonstration truss is identical to that of the model. Both the compression and tension tubular members consist of three sections, as follows:

(1) A uniform section of thin-walled Ti-6Al-4V annealed seam-welded tube reinforced with boron-epoxy

(2) A transition region which utilizes a stepped-joint concept to transfer loads from the composite to the titanium end fittings

(3) End fittings which are mechanically fastened directly to the joint cluster for compression members or which terminate as lugs for tension members

Figure 5 shows the internal load distribution used to design the structure, including the secondary loading induced by the displacement of the structure under load. The secondary loads, which include an end moment of $6380 \mathrm{~N}-\mathrm{m}$ (56.5 kip-in.), serve to demonstrate the moment-carrying capability of the tubular reinforced members. This capability is a design requirement of the shuttle structure for the applied-load cases with the engines in the gimbaled position.

The compression member of the demonstration truss shown in figure 6 consists of 16 layers of boron-epoxy (14 longitudinal, one at $0.785 \mathrm{rad}\left(45^{\circ}\right)$, and one at $-0.785 \mathrm{rad}$ ) on a $\mathrm{Ti}-6 \mathrm{Al}-4 \mathrm{~V}$ annealed tube having a $9.1-\mathrm{cm}(3.6-\mathrm{in}$.$) o.d. and a 0.066-\mathrm{cm}(0.026-i n$.) wall. Five additional plies of boron-epoxy are contained in the transition region to obtain a 15-percent margin of safety. The end fittings of the tube are rolled sheet stock chemmilled to final dimensions. Each of the shims shown in figure 6 is split at one point around the circumference. For assembly, the shims were expanded slightly and slipped into position over the boron-epoxy and film adhesive. The discontinuities in the shims were staggered around the tube.

The tension member of the truss (fig. 7) was fabricated by curing 18 layers of boron-epoxy (16 longitudinal, one at $0.785 \mathrm{rad}\left(45^{\circ}\right)$, and one at $-0.785 \mathrm{rad}$ ) on a $\mathrm{Ti}-6 \mathrm{Al}-4 \mathrm{~V}$ annealed tube having a $5.1-\mathrm{cm}(2.0-\mathrm{in}$.$) o.d. and an 0.084-\mathrm{cm}$ (0.033-in.) wall. The titanium substrate was butt-welded to machined end fittings prior to the addition of the boronepoxy.

\section{Subelement Specimens}

Three elements were designed for fabrication and test prior to manufacturing the demonstration truss in order to verify experimentally the basic design and analysis of the stepped joint transition region. The tension specimen is identical to the tension member of the demonstration truss shown in figure 7. The compression subelement shown in figure 8 was selected to demonstrate the joint concept for the all-composite design discussed in appendix B. The compression subelement shown in figure 9 was selected to 
verify the joint concept for the 75 percent boron-epoxy, 25 percent titanium member of the demonstration truss. The stepped shim joints for the all-composite tube were fabricated from Ti-6Al-6V-2Sn annealed. This higher strength alloy was used instead of Ti-6Al-4V annealed because no welding was required for this design.

Three precautions were taken against bearing failure of the boron-epoxy at the end of the compression specimens, as shown in figures 8 and 9. First, three longitudinal plies of boron-epoxy were added to the end of the specimens to reduce the bearing stress. Second, a $0.5-\mathrm{cm}-(0.2-\mathrm{in}-)$ thick tapered tab, $2.5 \mathrm{~cm}(1.0 \mathrm{in.})$ long, of circumferentialwrapped unidirectional fiber glass was located at the end of the tube. Finally, the inside of the specimens was filled with epoxy potting compound to a depth of $1.3 \mathrm{~cm}(0.5 \mathrm{in}$.$) .$ Load introduction at the opposite, all-titanium, end of the subelement was accomplished with two rows of bolts which are similar to those of the demonstration truss. Photographs of the two compression subelements are shown in figure 10.

\section{SPECIMEN FABRICATION}

The composite-tube fabrication procedures represent a modification to a process developed at Langley Research Center (ref. 8) which utilizes a heat-shrinkable teflon sleeve over the composite and an oven cure. After considerable development effort, a fabrication procedure which includes a bleeder system and autoclave curing was selected for the manufacture of specimens.

The boron-epoxy prepreg was laid up on the titanium substrate for the compositereinforced specimens and directly on a male mandrel for the all-composite specimens. Additional resin was added to the inside of the first ply to decrease the porosity and improve the tack. This additional resin also increases the strength of the bond to the titanium substrate. Each ply was laid in place with the scrim cloth down and was manually compacted. The composite laminate was covered with a thin-weave nylon peel ply and heat-shrinkable nylon bleeder plies, as required for the particular laminate. This entire package was bagged with a heat-shrinkable teflon sleeve and cured in an autoclave by drawing a vacuum through the bleeder system and using the manufacturer's recommended cure cycle. Composite tubes thus processed exhibited approximately a 0.50 filament volume fraction and a uniform wall thickness.

During manufacturing-process development efforts, it was discovered that transverse residual stresses could cause longitudinal cracks to develop in the composite material of the reinforced tube wall. These residual stresses result from the required elevated temperature cure of the composite and the dissimilarities of the constituent material coefficients of thermal expansion. Tubes with 75 percent composite by volume experienced critical residual stresses. Subsequently, composite-reinforced specimens were 
designed with a pair of plies at $0.785 \mathrm{rad}\left(45^{\circ}\right)$ on the exterior surface of the composite. These layers reduced the residual stresses and increased the circumferential strength of the boron-epoxy laminate.

The titanium substrate for the composite-reinforced specimens was rolled and seam-welded Ti-6Al-4V annealed sheet stock. The welding process involved tungsten inert-gas fusion welding without the addition of filler rod material. The joint cluster was machined from a rolled billet of Ti-6Al-4V annealed material.

\section{METHOD OF TESTING}

The subelement specimens were tested in a $1340-\mathrm{kN}-(300-\mathrm{kip}-)$ capacity hydraulic test machine. Hardened steel disks were used between the test specimen and the machine platen for load introduction directly into the boron-epoxy composite in bearing. Prior to testing, the specimen was loaded to 20 percent of its anticipated failing load and the platen was alined to obtain an equal strain readout from the four gages placed around the circumference of the specimen. The tension element was tested as shown in figure 11.

The demonstration truss was tested by using a $1340-\mathrm{kN}-(300-\mathrm{kip}-)$ capacity portable hydraulic test machine as shown in figure 12. The truss was mounted on a vertical rigid wall and loaded directly under the joint cluster with a vertical load applied by the jack. A system of rollers was used to permit horizontal and rotational motion in the plane of the truss at the load introduction point. The out-of-plane deflection of the joint cluster was restricted with tension cables (not shown in the figure) oriented perpendicular to the plane of the truss and anchored to the support wall. The demonstration truss was loaded to approximately 50 percent of design ultimate load at a load rate of $134 \mathrm{kN}$ (30 kips) per minute and then unloaded. Strain-gage outputs were checked to verify that the desired internal load distribution had been obtained. The demonstration truss was then loaded to failure at the same load rate.

Foil strain gages were located on all specimens as required to determine strain distributions and to help detect buckling of the compression specimens. The strain-gage data were recorded during test with the use of the Langley central digital data recording facility. All specimens were loaded at a constant load rate to failure. The load rate used for each particular specimen was that which corresponded to an initial strain rate of 0.001 per minute. All testing was conducted at room temperature.

\section{TEST RESULTS AND DISCUSSION}

\section{Subelement Specimens}

The design ultimate load, the experimental failure load, and the specimen parameters are presented in table III for all the compression subelements and the tension ele- 
ment. The all-composite compression subelement failed at $734 \mathrm{kN}$ (165 kips) or 93 percent of design ultimate load. The failure occurred in the transition region and resulted from the buckling of the outermost titanium shim at its discontinuity. It appears that an overall increase in the titanium thickness of the tube end or a reapportionment of the internal shim thicknesses to reduce the degree of discontinuity in the external shim could improve this situation. Efforts along these lines were not pursued in the present study because shim buckling was considered unlikely for the composite-reinforced designs which are of primary interest. Because of its lower compressive yield stress, the titanium alloy used in the composite-reinforced designs is not stressed to the level at which this shim buckled.

The first composite-reinforced compression subelement failed at $687 \mathrm{kN}$ (155 kips) or 87 percent of design ultimate load. This failure occurred at the end of the specimen by brooming of the fibers. This test was repeated with a new specimen and it failed at $653 \mathrm{kN}$ (147 kips). The onset of buckling of the titanium substrate occurred at a load of $490 \mathrm{kN}$ (110 kips). An inadequate bond between the boron-epoxy and the titanium resulted in the premature failure. Investigation revealed that this specimen was fabricated without additional epoxy resin under the first ply. Although these specimens failed to meet the ultimate load requirement, analysis of the modes of failure established sufficient confidence in the design and fabrication procedures to warrant suspension of further subelement tests.

The tension element failed at $603 \mathrm{kN}$ (136 kips) or 113 percent of design ultimate load. The failure occurred at the center section of the member away from the bondedjoint transition regions as shown in figure 13. This location of failure was anticipated due to the higher margins of safety utilized in the transition regions and end-fitting designs. The failure occurred at a stress level of $1190 \mathrm{MN} / \mathrm{m}^{2}(163 \mathrm{ksi})$ in the tube wall.

Axial strains along the transition regions of the compression and tensile specimens are compared with strains calculated by use of the analysis of reference 6 in figures 14 and 15, respectively. There is good agreement between the calculated and experimental strains for all the subelement tests. This agreement shows that the assumption of negligible bending in the joint region is applicable. In addition, for the compression specimen in which the multiple-shim stepped joint was used, the test results demonstrate that the effects of the bondlines between the shims are negligible as was assumed in the analysis.

\section{Demonstration Truss}

The demonstration truss failed at a load of $917 \mathrm{kN}$ (206 kips), 118 percent of design ultimate load. Failure occurred in the center section of the tension member as shown in 
figure 16. A tension failure of the composite material probably initiated the fracture and debonding between the boron-epoxy and the titanium substrate. It is unlikely that the failure started in the titanium, because it was stressed to less than 80 percent of its ultimate stress. The failure continued through the titanium substrate at a location near the butt weld. This mode of failure was similar to that of the tension element (fig. 13). After testing, a visual inspection revealed no evidence of failure in the compression member or the joint cluster. Strain-gage data recorded during the test indicate that the compression member had been loaded to 113 percent of design ultimate load.

\section{Projected Weight Saving}

Weight estimates for a full-size planar truss of the configuration shown in figure 3 are included in table IV for an all-titanium design and a boron-epoxy-reinforced-titanium design. Both the titanium and the boron-epoxy-reinforced titanium tubular members were designed by utilizing the procedures previously described. The composite-reinforced members had a basic section of 75 percent boron-epoxy and 25 percent titanium by volume, similar to those of the demonstration truss. The weights of end fittings required to attach the composite-reinforced tubular members to joint clusters are included in the member weights listed in table IV and were estimated by scaling up the appropriate designs of the demonstration truss. End-fitting weight was assumed to be directly proportional to the member load raised to the three-halves power. This scaling factor was derived by noting that the required cross-sectional areas of the fasteners and end fittings are directly proportional to the member load, whereas the end-fitting length required to prevent shear out of the fasteners is proportional to the square root of the member load. The titanium compression members were uniformly welded tubes with no additional material needed for load introduction and, therefore, included no end fitting. The joint cluster weights were estimated by using the basic design of the test-article joint cluster. These weights were then scaled up for load and to account for interference problems associated with larger diameter members. Fastener weights are included in the joint cluster weights.

A weight saving of $96.8 \mathrm{~kg}(213 \mathrm{Ibm})$ was calculated for the members. An additional saving of $18.3 \mathrm{~kg}(40 \mathrm{lbm})$ is shown for the joint clusters. This saving results from the composite-reinforced designs being of a smaller diameter than the optimum titanium compression members and therefore requiring smaller connectors. The total weight saving for the full-scale planar truss amounts to 24 percent of the truss weight. It is expected that a similar weight saving could be achieved on the entire booster thrust structure. 


\section{CONCLUSIONS}

An analytical and experimental study has been conducted to demonstrate the weightsaving potential of composite-reinforced titanium tubular members for a space shuttle booster thrust structure. Results of the study showed that:

1. Development tests of subelements based on preliminary design are essential to insure satisfactory performance of the final, detailed design.

2. The addition of a pair of angle plies to the outside of the longitudinally oriented boron-epoxy reinforcement of a titanium tube was found to prevent laminate cracking caused by transverse residual curing stresses.

3. Addition of a resin or adhesive layer between the boron-epoxy prepreg and the titanium substrate tube was found to decrease joint porosity and increase bond strength.

4. A multiple-shim, multiple-step joint concept provided a satisfactorily designed transition region for transferring loads from the boron-epoxy composite to the titanium end fittings.

5. Additional experimental data on the local buckling strength of cylinders with diameter-thickness ratios in the range of interest for highly loaded, optimum-design composite cylinders $(\mathrm{D} / \mathrm{t} \approx 50)$ are needed for efficient design. The limited tests in this study failed prematurely due to improper end constraints with no indication of local buckling at an experimental/theoretical correlation factor of 0.58 .

6. Results of the subelement and local buckling tests have been applied to the design of a heavily loaded, composite-reinforced metal tubular truss structure. Comparative designs indicated that the composite-reinforced titanium truss weighed 24 percent less than an equivalent all-titanium truss.

7. A demonstration truss with one compression member and one tension member of boron-epoxy-reinforced titanium and an interconnecting titanium joint cluster was designed, fabricated, and tested. Failure occurred in the tension member at 118 percent of design ultimate load.

\section{Langley Research Center,}

National Aeronautics and Space Administration, Hampton, Va., April 26, 1972. 


\section{APPENDIX A}

\section{CONVERSION OF U.S. CUSTOMARY UNITS TO SI UNITS}

The International System of Units (SI) was adopted by the Eleventh General Conference on Weights and Measures, Paris, October 1960, in Resolution No. 12 (ref. 2). Conversion factors for the units used herein are given in the following tables:

\begin{tabular}{|c|c|c|c|}
\hline Physical quantity & $\begin{array}{l}\text { U.S. Customary } \\
\text { Unit }\end{array}$ & $\begin{array}{c}\text { Conversion } \\
\text { factor } \\
(*)\end{array}$ & SI Unit \\
\hline Angle & degrees & $1.745 \times 10^{-2}$ & radians (rad) \\
\hline Bending moment & kip-in. & $1.130 \times 10^{2}$ & newton-meters $(\mathrm{N}-\mathrm{m})$ \\
\hline Density & $\mathrm{lbm} / \mathrm{in}^{3}$ & $2.768 \times 10^{4}$ & kilograms per cubic meter $\left(\mathrm{kg} / \mathrm{m}^{3}\right)$ \\
\hline Force & $\mathrm{kip}=1000 \mathrm{lbf}$ & $4.448 \times 10^{3}$ & newtons $(\mathrm{N})$ \\
\hline Length & in. & $2.54 \times 10^{-2}$ & meters $(\mathrm{m})$ \\
\hline Mass & $\mathrm{lbm}$ & $4.536 \times 10^{-1}$ & kilograms (kg) \\
\hline Moduli and stress & $\mathrm{ksi}=\mathrm{kips} / \mathrm{in}^{2}$ & $6.895 \times 10^{6}$ & newtons per square meter $\left(\mathrm{N} / \mathrm{m}^{2}\right)$ \\
\hline
\end{tabular}

*Multiply value given in U.S. Customary Unit by conversion factor to obtain equivalent value in SI Unit.

Prefixes to indicate multiple of units are as follows:

\begin{tabular}{|c|c|}
\hline Prefix & Multiple \\
\hline centi (c) & $10^{-2}$ \\
\hline kilo (k) & $10^{3}$ \\
\hline mega $(\mathrm{M})$ & $10^{6}$ \\
\hline giga (G) & $10^{9}$ \\
\hline
\end{tabular}




\section{APPENDIX B}

\section{COST-WEIGHT COMPARISON OF BORON-EPOXY-REINFORCED}

\section{TITANIUM TUBULAR COLUMNS}

The composite-reinforced tubular concept investigated in this study offers to the designer a variable weight saving which is dependent upon the percentage of composite material used. As the percentage of composite is increased, both the weight saving and the unit cost of that weight saving are increased. The relation between cost and weight is shown in figure 17 for a typical compression member designed as a uniform boronepoxy-reinforced titanium tube. The slope of the curve presented in figure 17 shows the incremental cost for each successive increment of weight saved. Note that the application of a small percentage of boron-epoxy reinforcement is extremely efficient in terms of weight saved per pound of boron-epoxy used. At the other extreme, for high percentages of reinforcement, the last increments of weight savings that are achievable are quite costly.

The composite-reinforced columns represented in figure 17 were designed with boron-epoxy reinforcement on the outside of a titanium tubular substrate. For comparison purposes an all-composite column was included in the figure. Manufacturing costs were determined on a production-cost basis by using the costs shown in figure 17 .

Two families of laminate orientations for the wall of the all-composite compression tube were investigated to determine the lowest weight design. For each orientation the optimization procedure of appendix $\mathrm{C}$ was used to determine the critical stress corresponding to the minimum-weight design. This stress is plotted in figure 18 . The first family of laminates investigated included longitudinal plies and plies oriented at angles of $\pm 0.785 \mathrm{rad}\left( \pm 45^{\circ}\right)$ and $1.57 \mathrm{rad}\left(90^{\circ}\right)$ to the axis of the tube. The results of this investigation are shown in figure 18(a). The sharp breaks in the curves result from a change in the mode for local buckling. The minimum-weight design is shown to have approximately 60 percent of the plies longitudinal and 40 percent of the plies oriented at $\pm 0.785 \mathrm{rad}\left( \pm 45^{\circ}\right)$ to the axis of the tube. The second family of laminates was investigated to determine whether the design could be improved by varying the orientations of the angle plies. The results are shown in figure 18(b). The flatness of these curves in the area of maximum stress indicates that columns of approximately equal weight could be designed with different angle-ply orientations. The laminate orientation selected for use in the cost-weight study consists of 60 percent longitudinal plies and 40 percent $\pm 0.785 \mathrm{rad}\left( \pm 45^{\circ}\right)$ plies. 


\section{COMPRESSION TUBE OPTIMIZATION}

The problem of optimizing the configuration of a tubular member which is subject to axial load only (column) or to axial load and bending moment (beam column) was solved in this study for homogeneous orthotropic materials. The beam column configuration and loading is shown in figure 19. This optimization was used to design all compression members (titanium, boron-epoxy-reinforced titanium, and boron-epoxy).

The critical buckling stress for overall (column) instability, including the shear deflection term, with both ends simply supported is

$$
\sigma_{c}=\frac{\sigma_{e}}{1+\frac{2}{G_{L T}} \sigma_{e}}
$$

where

$$
\sigma_{e}=\frac{\pi^{2} E_{L} r^{2}}{2 L^{2}}
$$

and

$\mathrm{G}_{\mathrm{LT}} \quad$ in-plane shear modulus

$\mathrm{E}_{\mathrm{L}} \quad$ longitudinal modulus of elasticity

$\mathrm{r} \quad$ mean radius

L tube length

The local buckling stress for circular cylindrical tubes (refs. 3 and 5) is

$$
\sigma_{\mathrm{cr}}=\frac{\gamma \mathrm{K} \phi \sqrt{\mathrm{E}_{\mathrm{L}} \mathrm{E}_{\mathrm{T}}}}{2 \mathrm{r} / \mathrm{t}}
$$

where

$$
\mathrm{K}=2\left[3\left(1-\nu_{\mathrm{TL}} \nu_{\mathrm{LT}}\right)\right]^{-1 / 2}
$$


and

$$
\phi=\left[\frac{2 \mathrm{G}_{\mathrm{LT}}}{\sqrt{\mathrm{E}_{\mathrm{L}} \mathrm{E}_{\mathrm{T}}}}\left(1+\sqrt{\nu_{\mathrm{TL}}{ }^{\nu} \mathrm{T}}\right)\right]^{1 / 2}
$$

or

$$
\phi=1
$$

whichever is less, and

$\gamma \quad$ correlation factor

$\mathbf{E}_{\mathbf{T}} \quad$ transverse modulus of elasticity

$\nu_{\mathrm{LT}} \quad$ major Poisson's ratio

$\nu_{\text {TL }} \quad$ minor Poisson's ratio

t cylinder wall thickness

The effect of the low shear stiffness of the tube is included in the factor $\phi$ which is equal to unity for the axisymmetric buckling mode or has the value obtained from equation (C5) for the antisymmetric modes (ref. 3). The empirical factor $\gamma$ is included to correlate predicted values with test results.

The maximum compressive stress for a pin-ended column with applied end moments $M_{1}$ and $M_{2}$ and axial load $P$ is

$$
\sigma_{\max }=\sigma\left(1+\frac{2 \mathbf{M}_{\max }}{\operatorname{Pr}}\right)
$$

where the maximum bending moment, from table 14:3 of reference 9 , with the sign convention shown in figure 19 is

$$
M_{\max }=\left[\left(\frac{M_{2}-M_{1} \cos \beta}{\sin \beta}\right)^{2}+M_{1}^{2}\right]^{1 / 2}
$$


where

$$
\begin{aligned}
& \beta=\pi \sqrt{\sigma / \sigma_{\mathbf{c}}} \\
& \sigma=\frac{\mathbf{P}}{\mathbf{A}}
\end{aligned}
$$

and $\mathrm{A}$ is defined as the column cross-sectional area.

By use of the definition of the nominal stress $\sigma$, the Euler buckling stress can be written

$$
\sigma_{e}=\frac{\pi E_{L}}{4 \sigma} \frac{P}{L^{2}} \frac{r}{t}
$$

Solving equation (C3) for $r / t$ and substituting into equation (C10) gives

$$
\sigma_{\mathrm{e}}=\frac{\pi \mathrm{E}_{\mathrm{L}} \gamma \mathrm{K} \phi \sqrt{\mathrm{E}_{L} \mathrm{E}_{\mathrm{T}}}}{8 \sigma \sigma_{c r}} \frac{\mathrm{P}}{L^{2}}
$$

and the column buckling stress (eq. (C1)) can be written as

$$
\sigma_{c}=\left[\frac{8 \sigma \sigma_{c r}}{\pi \mathrm{E}_{\mathrm{L}} \gamma \mathrm{K} \phi \sqrt{\mathrm{E}_{\mathrm{L}} \mathrm{E}_{\mathrm{T}}\left(\mathrm{P} / \mathrm{L}^{2}\right)}}+\frac{2}{\mathrm{G}_{\mathrm{LT}}}\right]^{-1}
$$

Substituting equation (C12) into the definition for $\beta$ gives

$$
\beta=\pi\left\{\sigma\left[\frac{8 \sigma \sigma_{c r}}{\pi \mathrm{E}_{\mathrm{L}} \gamma \mathrm{K} \phi \sqrt{\mathrm{E}_{\mathrm{L}} \mathrm{E}_{\mathrm{T}}}\left(\mathrm{P} / \mathrm{L}^{2}\right)}+\frac{2}{\mathrm{G}_{\mathrm{LT}}}\right]\right\}^{1 / 2}
$$

Solving for the mean radius of the tube with equation (C3) and the definition of the nominal stress gives

$$
\mathbf{r}=\left(\frac{\gamma \mathrm{K} \phi \sqrt{\mathrm{E}_{\mathrm{L}} \mathrm{E}_{\mathrm{T}} \mathrm{P}}}{4 \pi \sigma \sigma_{\mathrm{cr}}}\right)^{1 / 2}
$$


Substituting into equation (C6) gives

$$
\sigma_{\max }=\sigma\left\{1+\frac{4}{\mathrm{PL}}\left[\frac{\pi \sigma \sigma_{\mathrm{cr}}}{\gamma \mathrm{K} \phi \sqrt{\mathrm{E}_{\mathrm{L}} \mathrm{E}_{\mathrm{T}}}\left(\mathrm{P} / \mathrm{L}^{2}\right)}\right]^{1 / 2}\left[\left(\frac{\mathrm{M}_{2}-\mathrm{M}_{1} \cos \beta}{\sin \beta}\right)^{2}+\mathrm{M}_{1}^{2}\right]^{1 / 2}\right\}
$$

with $\beta$ being given by equation (C13).

The minimum-weight beam column is now found by setting the maximum applied stress $\sigma_{\max }$ equal to the local buckling stress $\sigma_{\mathrm{cr}}$. Equation (C15) is now a single relation between $\sigma$ and $\sigma_{\mathrm{cr}}$ which is used to search for the maximum value of $\sigma$ by varying $\sigma_{\mathrm{cr}}$. The range of variation of $\sigma_{\mathrm{cr}}$ which must be searched is bounded by the value of $\sigma_{\mathrm{cr}}$ associated with the optimum column $\left(\mathbf{M}_{1}=\mathbf{M}_{2}=0\right)$ and the compression ultimate stress. The local buckling stress for the optimum column $\sigma_{\mathrm{cr}}$ is found by equating the nominal stress to the local buckling stress and the column buckling stress $\left(\sigma=\sigma_{\mathrm{cr}}=\sigma_{\mathrm{c}}\right)$. Therefore, $\beta$ is set equal to $\pi$, and equation (C15) is no longer applicable. The optimum column is found by solving the following equation for $\sigma_{\text {col }}$ :

$$
\frac{8 \sigma_{\mathrm{col}}^{3}}{\pi \mathrm{E}_{\mathrm{L}} \gamma \mathrm{K} \phi \sqrt{\mathrm{E}_{\mathrm{L}} \mathrm{E}_{\mathrm{T}}}\left(\mathrm{P} / \mathrm{L}^{2}\right)}+\frac{2 \sigma_{\mathrm{col}}}{\mathrm{G}_{\mathrm{LT}}}=1
$$

Once the maximum value of $\sigma$ and the related value of $\sigma_{\mathrm{cr}}$ are found, the geometrical configuration of the tube can be found from equation (C14) and $A=P / \sigma$.

A computer program using this procedure has been written which yields the configuration of the optimum tube and of other tubes that are near optimum. These additional configurations enable the designer to vary the tube design parameters which affect the weight of other structural components, particularly the joint clusters. In this manner the designer can achieve a near-optimum structural configuration. 


\section{APPENDIX D}

\section{CYLINDER BUCKLING TESTS}

In order to establish a correlation between theoretical and experimental data on cylinder buckling for a low $\mathrm{D} / \mathrm{t}$ range, the following cylinder buckling test program was utilized. Five basic tubular buckling specimens were fabricated for axial compression tests. Geometrical parameters and laminate orientation for each specimen are included in table V. All specimens were designed with small $L / D$ values (1 to 3.6) to insure failure in the local buckling mode.

Two of the specimens fabricated were $10 \mathrm{~cm}$ (4 in.) in length, one all-composite and one composite-reinforced titanium which is shown in figure 20. Three additional 33-cm(13-in-) long composite-reinforced titanium specimens were also fabricated. These specimens (fig. 21) were designed with a greater length in an attempt to obtain buckling failures away from the ends of the cylinders where the effects of the supports and rotational restraints are most marked. The precautions taken against bearing failure of the subelement specimens (i.e., fiber-glass tabs, potting, and additional plies) were also included in the design of all the local buckling specimens.

The local buckling specimens were tested in a $1340-\mathrm{kN}-(300-\mathrm{kip}-)$ capacity hydraulic test machine by using the procedure described previously. The test setup is shown in figure 22 .

Typical strain-gage data are presented in figure 23 for both a $10-\mathrm{cm}$ (4-in.) and a $33-\mathrm{cm}$ (13-in.) composite-reinforced specimen. The data for the $10-\mathrm{cm}$ specimen indicate that bending was present in the test section from the onset of loading whereas the data for the $33-\mathrm{cm}$ cylinder shows no evidence of bending in the center of the test section. The failure of the longer specimens began at the edge of the fiber-glass tabs and was attributed to the presence of bending moments at the tube ends. This bending is shown in the strain-gage readings at the tab edge (fig. 23) and the failure, as shown in figure 24, is an end failure. The test data for these longer local buckling test specimens (table V) show an average correlation factor of 0.58 . Since these failures occurred prior to buckling of the test section, and the strain-gage data indicated that a local buckling failure was not imminent, this correlation factor is expected to be too low. The value given in reference 5 for the appropriate value of $\mathrm{D} / \mathrm{t}$ is 0.79 . The compression member of the demonstration truss was designed with a correlation factor of 0.6 . 


\section{REFERENCES}

1. Zender, George W.; and Dexter, H. Benson: Compressive Properties and Column Efficiency of Metals Reinforced on the Surface With Bonded Filaments. NASA TN D-4878, 1968.

2. Comm. on Metric Pract.: ASTM Metric Practice Guide. NBS Handbook 102, U.S. Dep. Com., Mar. 10, 1967.

3. Dow, Norris F.; and Rosen, B. Walter: Structural Efficiency of Orthotropic Cylindrical Shells Subjected to Axial Compression. AIAA J., vol. 4, no. 3, Mar. 1966, pp. 481-485.

4. Card, Michael F.: Experiments To Determine the Strength of Filament-Wound Cylinders Loaded in Axial Compression. NASA TN D-3522, 1966.

5. Anon.: Buckling of Thin-Walled Circular Cylinders. NASA SP-8007, 1965. (Revised 1968.)

6. Corvelli, N.; and Saleme, E.: Analysis of Bonded Joints. Rep. No. ADR 02-01-70.1, Grumman Aerosp. Corp., July 1970.

7. Bruhn, E. F.: Analysis and Design of Flight Vehicle Structures. Tri-State Offset Co., c. 1965.

8. Davis, John G., Jr.: Fabrication of Uniaxial Filament-Reinforced Epoxy Tubes for Structural Applications. Advanced Techniques for Material Investigation and Fabrication, SAMPE Vol. 14, Soc. Aerosp. Mater. Process Eng., c.1968.

9. Niles, Alfred S.; and Newell, Joseph S.: Airplane Structures. Vol. II, Third ed., John Wiley \& Sons, Inc., c.1943, p. 94. 
TABLE I.- ROOM-TEMPERATURE DESIGN ALLOWABLES AND MATERIAL

PROPERTIES OF RIGIDITE 5505 BORON-EPOXY

[Single-ply properties]

Longitudinal tension strength, $\mathrm{MN} / \mathrm{m}^{2}$ (ksi) . . . . . . . . . . 1230

Longitudinal compression strength, $\mathrm{MN} / \mathrm{m}^{2}$ (ksi) . . . . . . . . . 1720

Longitudinal compression modulus, $\mathrm{GN} / \mathrm{m}^{2}$ (ksi) . . . . . . . . . 220

Longitudinal tension modulus, $\mathrm{GN} / \mathrm{m}^{2}(\mathrm{ksi}) \ldots \ldots \ldots . \ldots \ldots 212$

Transverse modulus, GN $/ \mathrm{m}^{2}$ (ksi) ................ 20

Shear modulus, GN $/ \mathrm{m}^{2}$ (ksi) ................... 8 (1200)

Major Poisson's ratio . . . . . . . . . . . . . . . 0.250

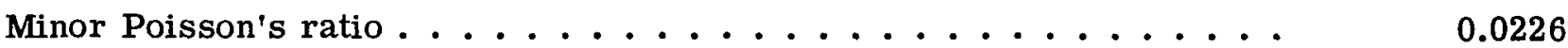

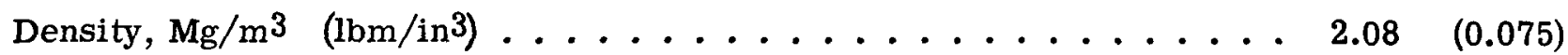

Average layer thickness, $\mathrm{cm}$ (in.) . . . . . . . . . $0.0132 \quad(0.0052)$

TABLE II.- ROOM-TEMPERATURE DESIGN ALLOWABLES AND MATERIAL PROPERTIES OF TITANIUM ALLOYS

\begin{tabular}{|c|c|c|c|c|}
\hline \multirow{2}{*}{ Property } & \multicolumn{4}{|c|}{ Sheet alloy } \\
\hline & $\mathrm{Ti}-6 \mathrm{Al}-$ & $4 \mathrm{~V}$ annealed & Ti-6Al-6 & $-2 \mathrm{Sn}$ annealed \\
\hline Tension ultimate, $\mathrm{MN} / \mathrm{m}^{2}$ (ksi) $\ldots \ldots$ & 959 & (139) & 1100 & (160) \\
\hline Tension yield, $\mathrm{MN} / \mathrm{m}^{2} \quad(\mathrm{ksi}) \quad \ldots$ & 903 & (131) & 1025 & (149) \\
\hline Compression yield, $\mathrm{MN} / \mathrm{m}^{2}$ (ksi) & 951 & (138) & 1110 & (161) \\
\hline Compression proportional limit, $\mathrm{MN} / \mathrm{m}^{2}$ & & & & \\
\hline$(\mathrm{ksi}) \ldots \ldots \ldots \ldots \ldots$ & 827 & (120) & $-\ldots$ & $\cdots--$ \\
\hline Bearing ultimate, $\mathrm{MN} / \mathrm{m}^{2} \quad(\mathrm{ksi}) \ldots$ & 1800 & (261) & 2110 & (306) \\
\hline Young's modulus, GN $/ \mathrm{m}^{2} \quad$ (ksi) $\ldots$ & 110 & $\left(\begin{array}{ll}16 & 000\end{array}\right)$ & 110 & $\left(\begin{array}{ll}16 & 000\end{array}\right)$ \\
\hline Shear modulus, GN $/ \mathrm{m}^{2}$ (ksi) $\ldots \ldots$ & 43 & $(6200)$ & 39 & $(5700)$ \\
\hline Density, $\mathrm{Mg} / \mathrm{m}^{3} \quad\left(\mathrm{lbm} / \mathrm{in}^{3}\right) \ldots \ldots$ & 4.44 & $(0.16)$ & 4.54 & $(0.164)$ \\
\hline
\end{tabular}


TABLE III.- EXPERIMENTAL AND CALCULATED RESULTS FOR SUBELEMENT TEST SPECIMENS

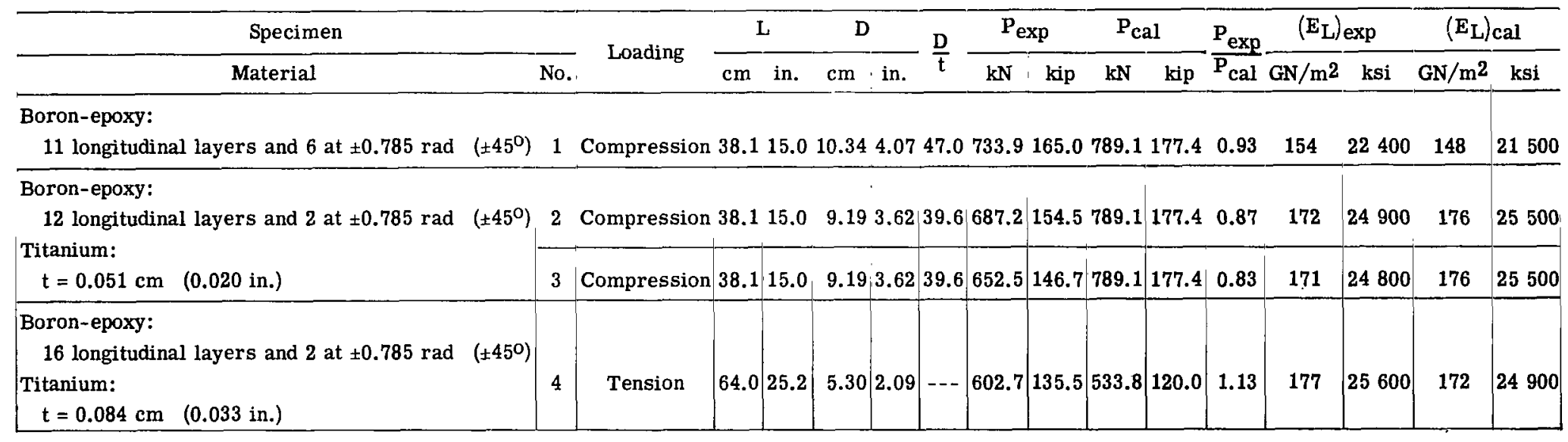


TABLE IV.- PROJECTED WEIGHTS AND WEIGHT SAVINGS FOR FULL-SCALE PLANAR TRUSS

\begin{tabular}{|c|c|c|c|c|c|c|}
\hline \multirow{2}{*}{$\begin{array}{l}\text { Truss } \\
\text { membera }\end{array}$} & \multicolumn{2}{|c|}{ Titanium design } & \multicolumn{2}{|c|}{$\begin{array}{l}\text { Composite-reinforced } \\
\text { designb }\end{array}$} & \multicolumn{2}{|c|}{ Weight saving } \\
\hline & $\mathrm{kg}$ & $\mathrm{lbm}$ & $\mathrm{kg}$ & $\mathrm{lbm}$ & $\mathrm{kg}$ & $\mathrm{lbm}$ \\
\hline $\mathrm{AD}$ and $\mathrm{CF}$ & 85.0 & 187.4 & 61.0 & 134.6 & 23.9 & 52.8 \\
\hline $\mathrm{BE}$ & 45.1 & 99.5 & 32.4 & 71.3 & 12.8 & 28.2 \\
\hline $\mathrm{DE}$ and $\mathrm{EF}$ & 65.3 & 144.0 & 46.6 & 102.4 & 18.9 & 41.6 \\
\hline $\mathrm{AB}$ and $\mathrm{BC}$ & 69.6 & 153.6 & 48.0 & 105.8 & 21.7 & 47.8 \\
\hline $\mathrm{BD}$ and $\mathrm{BF}$ & 63.1 & 139.2 & 43.5 & 96.2 & 19.5 & 43.0 \\
\hline Subtotal & 328.1 & 723.7 & 231.5 & 510.3 & 96.8 & 213.4 \\
\hline \multirow{2}{*}{$\begin{array}{l}\text { Joint } \\
\text { clustera }\end{array}$} & \multicolumn{2}{|c|}{ Titanium design } & \multicolumn{2}{|c|}{$\begin{array}{c}\text { Composite-reinforced } \\
\text { design }\end{array}$} & \multicolumn{2}{|c|}{ Weight saving } \\
\hline & $\mathrm{kg}$ & $1 \mathrm{bm}$ & $\mathrm{kg}$ & $1 \mathrm{bm}$ & $\mathrm{kg}$ & $\mathrm{lbm}$ \\
\hline $\mathrm{A}$ and $\mathrm{C}$ & 33.2 & 73.2 & 28.9 & 63.7 & 4.3 & 9.5 \\
\hline B & 38.9 & 85.7 & 32.6 & 71.7 & 6.4 & 14.0 \\
\hline $\mathrm{D}$ and $\mathrm{F}$ & 46.0 & 101.4 & 41.6 & 91.1 & 4.7 & 10.3 \\
\hline $\mathrm{E}$ & 29.6 & 65.3 & 26.8 & 59.0 & 2.9 & 6.3 \\
\hline Subtotal & 147.7 & 325.6 & 129.9 & 285.5 & 18.3 & 40.1 \\
\hline Total & $\overline{475.8}$ & $\overline{1049.3}$ & $\overline{361.4}$ & $\overline{795.8}$ & $\overline{115.1}$ & $\overline{253.5}$ \\
\hline
\end{tabular}

a Illustrated in figure 3.

b 75 percent boron-epoxy and 25 percent titanium. 
TABLE V.- EXPERIMENTAL AND CALCULATED RESULTS FOR LOCAL BUCKLING TEST SPECIMENS

\begin{tabular}{|c|c|c|c|c|c|c|c|c|c|c|c|c|c|c|c|}
\hline \multirow{2}{*}{$\frac{\text { Specimen }}{\text { Material }}$} & \multirow[b]{2}{*}{ No. } & \multicolumn{2}{|c|}{$\mathrm{L}$} & \multicolumn{2}{|l|}{$\mathrm{D}$} & \multirow{2}{*}{$\frac{D}{t}$} & \multicolumn{2}{|c|}{$\left(\sigma_{\mathrm{cr}}\right) \exp$} & \multicolumn{2}{|c|}{$\left(\sigma_{\mathrm{cr}}\right)_{\mathrm{cal}}$} & \multirow{2}{*}{$\frac{\left(\sigma_{\mathrm{cr}}\right) \exp }{\left(\sigma_{\mathrm{cr}}\right) \mathrm{cal}}$} & \multicolumn{2}{|c|}{$\left(E_{L}\right)_{\exp }$} & \multicolumn{2}{|c|}{$\left(\mathrm{E}_{\mathrm{L}}\right)_{\mathrm{cal}}$} \\
\hline & & $\mathrm{cm}$ & in. & $\mathrm{cm}$ & in. & & $\mathrm{MN} / \mathrm{m}^{2}$ & $\mathrm{ksi}$ & $\mathrm{MN} / \mathrm{m}^{2}$ & ksi & & $\mathrm{GN} / \mathrm{m}^{2}$ & ksi & $\mathrm{GN} / \mathrm{m}^{2}$ & $\mathrm{ksi}$ \\
\hline \multicolumn{16}{|l|}{ Boron-epoxy: } \\
\hline 9 longitudinal layers and 6 at $\pm 0.785 \mathrm{rad}\left( \pm 45^{\circ}\right)$ & 1 & 10.1 & 4.0 & 10.31 & 4.06 & 53.1 & 903.2 & 131.0 & 1641.0 & 238.0 & 0.55 & 141 & 20400 & 142 & 20600 \\
\hline $\begin{array}{l}\text { Boron-epoxy: } \\
12 \text { longitudinal layers and } 2 \text { at } \pm 0.785 \mathrm{rad} \quad\left( \pm 45^{\circ}\right) \\
\text { Titanium: } \\
t=0.051 \mathrm{~cm} \quad(0.020 \text { in. })\end{array}$ & 2 & 10.1 & 4.0 & 9.19 & 3.62 & 39.6 & 1275.6 & $185.0^{\circ}$ & 2103.0 & 305.0 & 0.61 & 167 & 24300 & 176 & 25500 \\
\hline \multirow{3}{*}{$\begin{array}{l}\text { Boron-epoxy: } \\
12 \text { longitudinal layers and } 2 \text { at } \pm 0.785 \mathrm{rad} \quad( \pm 45\end{array}$} & 3 & 33.0 & 13.0 & 9.27 & $3.65^{\prime}$ & 37.6 & 1289.4 & 187.0 & 2323.6 & 337.0 & 0.56 & 168 & 24400 & 172 & 24900 \\
\hline & 4 & 33.0 & 13.0 & 9.27 & 3.65 & 37.6 & 1316.9 & 191.0 & 2323.6 & 337.0 & 0.57 & 167 & 24200 & 172 & 24900 \\
\hline & 5 & 33.0 & 13.0 & 9.27 & 3.65 & 37.6 & 1420.4 & 206.0 & 2323.6 & 337.0 & 0.61 & 175 & 25400 & 172 & 24900 \\
\hline
\end{tabular}




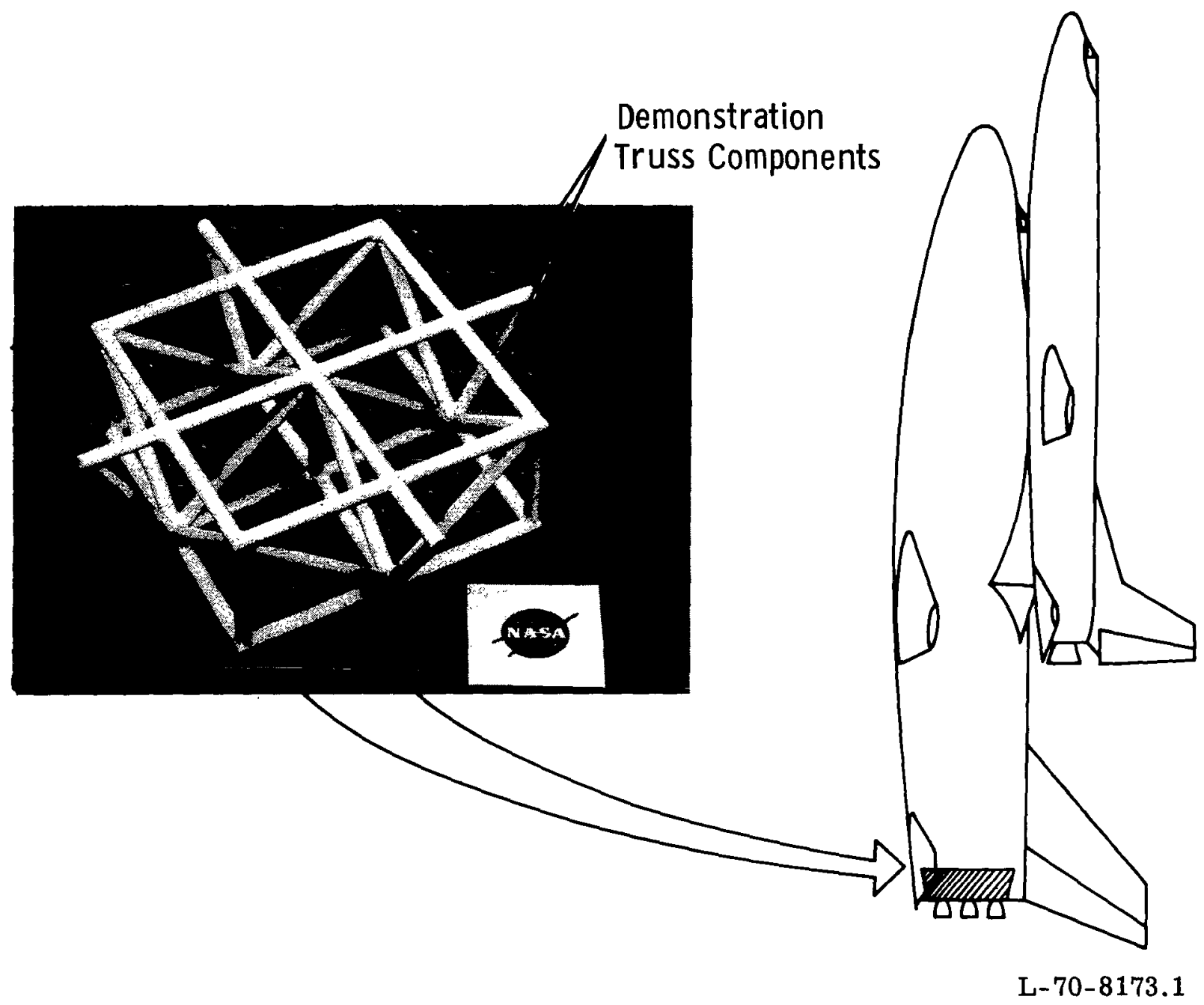

Figure 1.- Space shuttle booster thrust structure. 


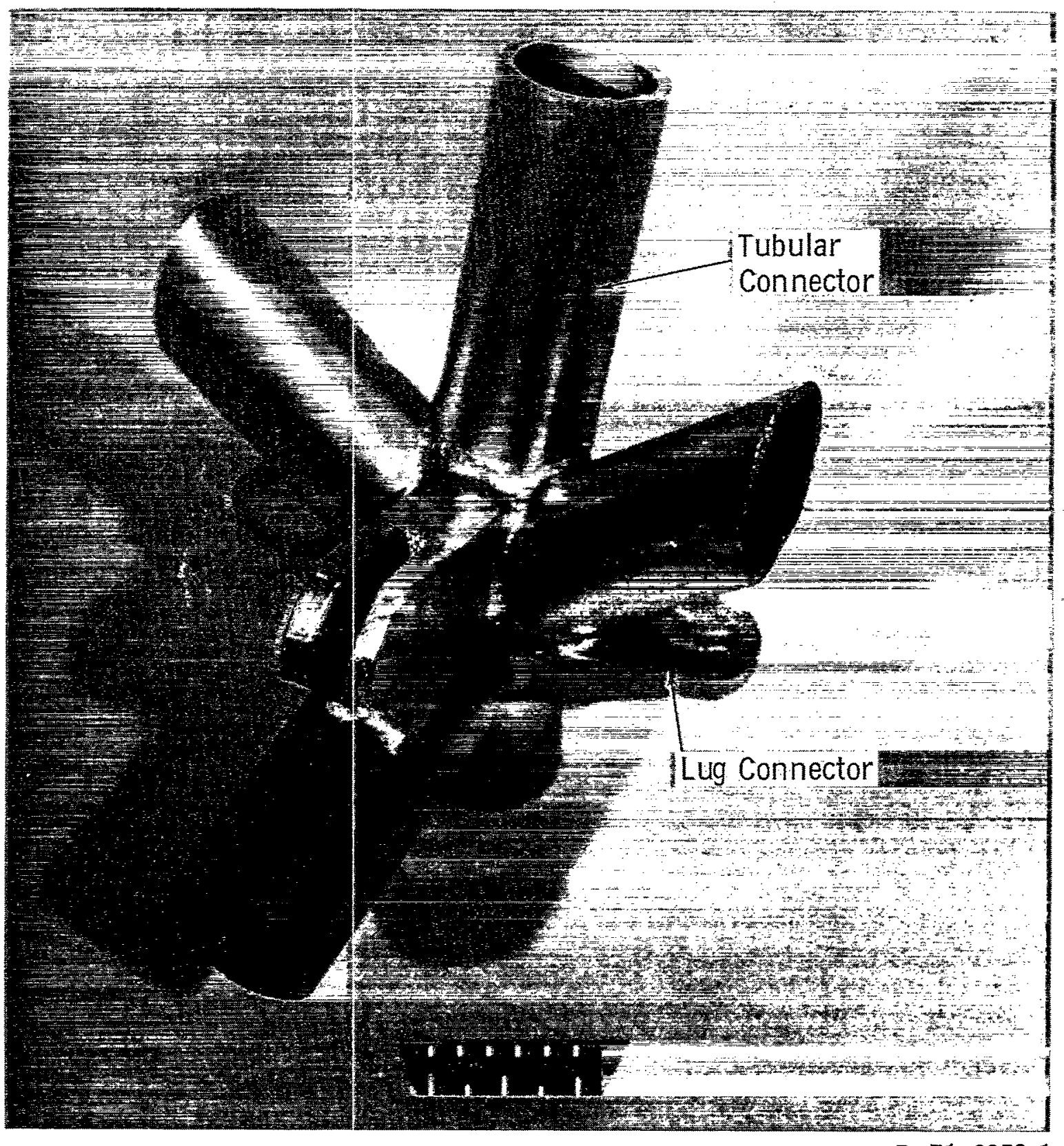

L-71-6052.1

Figure 2.- Model of three-dimensional joint cluster. 


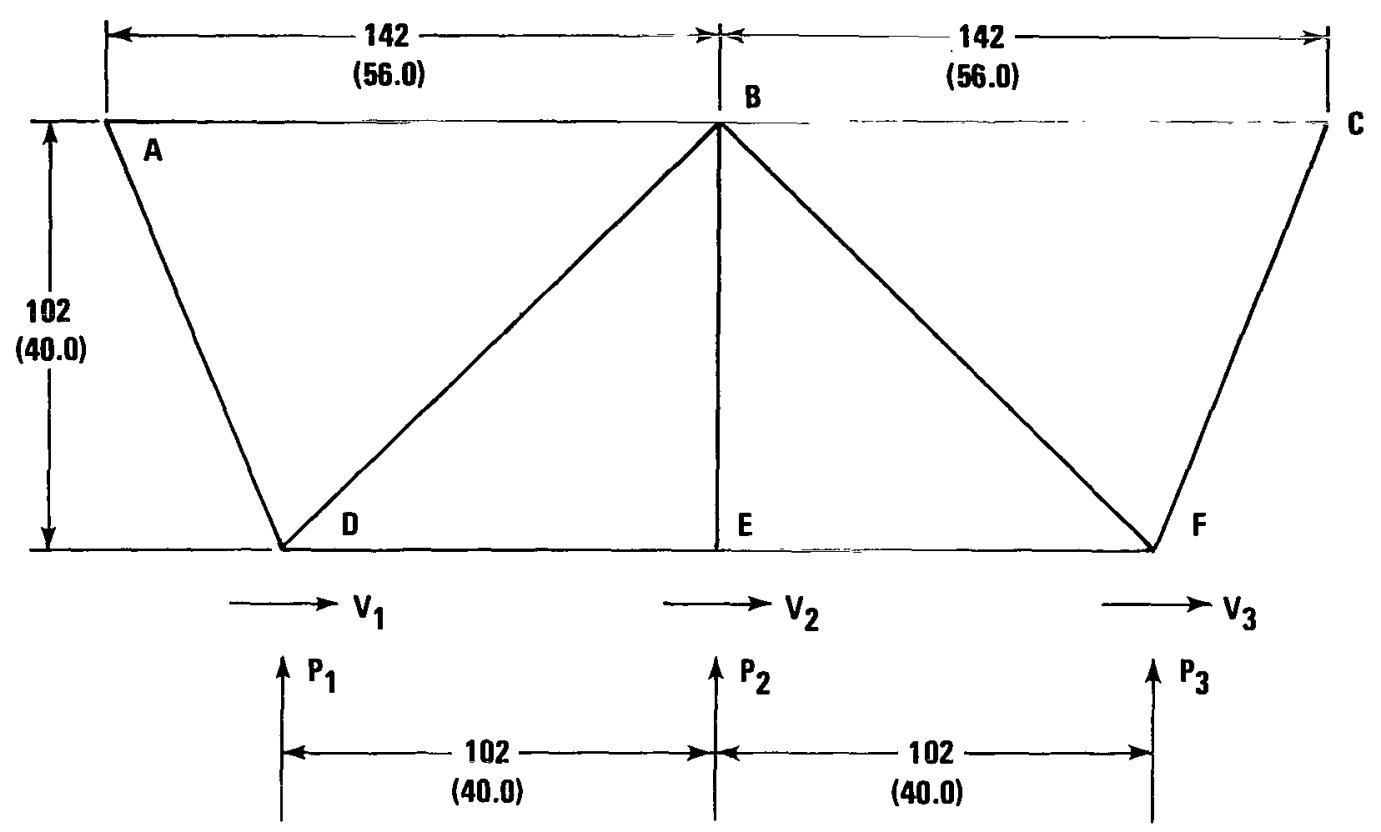

\begin{tabular}{|c|c|c|c|c|}
\hline & \multicolumn{4}{|c|}{ Ultimate Applied Loads and Member Loads } \\
\hline & \multicolumn{2}{|c|}{ Engines Symmetric } & \multicolumn{2}{|c|}{ Engines G imbaled* } \\
\hline & $\mathbf{k N}$ & kips & $\mathbf{k N}$ & kips \\
\hline $\mathbf{P}_{1}$ & 351.4 & 79.0 & 349.2 & 78.5 \\
\hline $\mathbf{P}_{2}$ & 482.2 & 108.4 & 478.2 & 107.5 \\
\hline $\mathbf{P}_{\mathbf{3}}$ & 351.4 & 79.0 & 349.2 & 78.5 \\
\hline$v_{1}$ & $\mathbf{0}$ & $\mathbf{0}$ & 42.7 & 9.6 \\
\hline$v_{2}$ & 0 & $\mathbf{0}$ & 58.7 & 13.2 \\
\hline$v_{3}$ & 0 & 0 & 42.7 & 9.6 \\
\hline$A B, B C$ & 285.6 & 64.2 & 537.3 & 120.8 \\
\hline$A D, C F$ & -636.1 & -143.0 & -789.1 & -177.4 \\
\hline$B D, B F$ & 340.7 & 76.6 & 505.3 & 113.6 \\
\hline DE, EF & -477.7 & -107.4 & -533.8 & -120.0 \\
\hline BE & -482.2 & -108.4 & -478.2 & -107.5 \\
\hline
\end{tabular}

* Plus moments due to shear loads being $15.2 \mathrm{~cm}(6.0 \mathrm{in})$ below center of joint

Figure 3.- Planar truss, idealized configuration, and loads. Dimensions are given in centimeters (inches). 


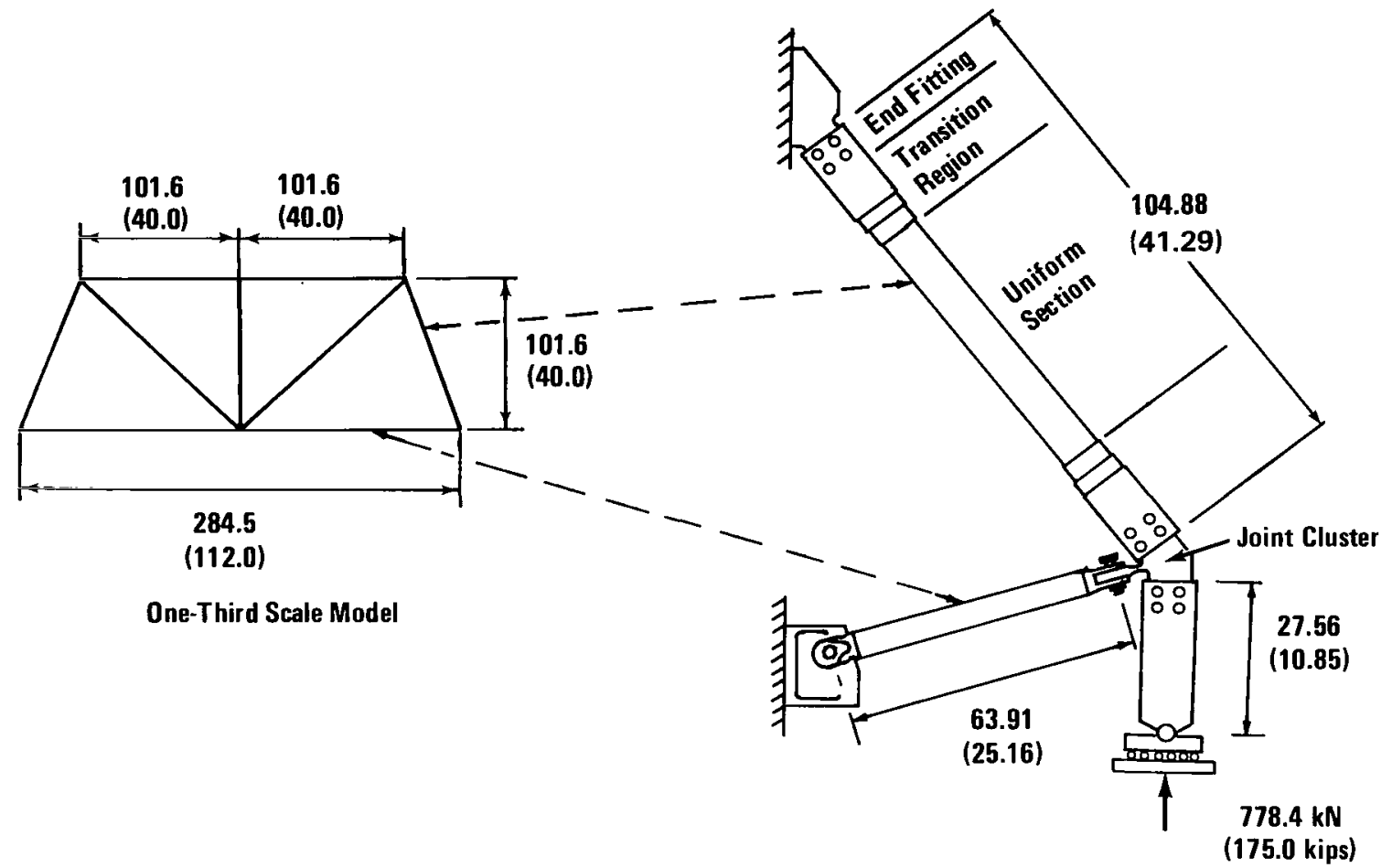

Figure 4.- Demonstration truss. Dimensions are given in centimeters (inches). 


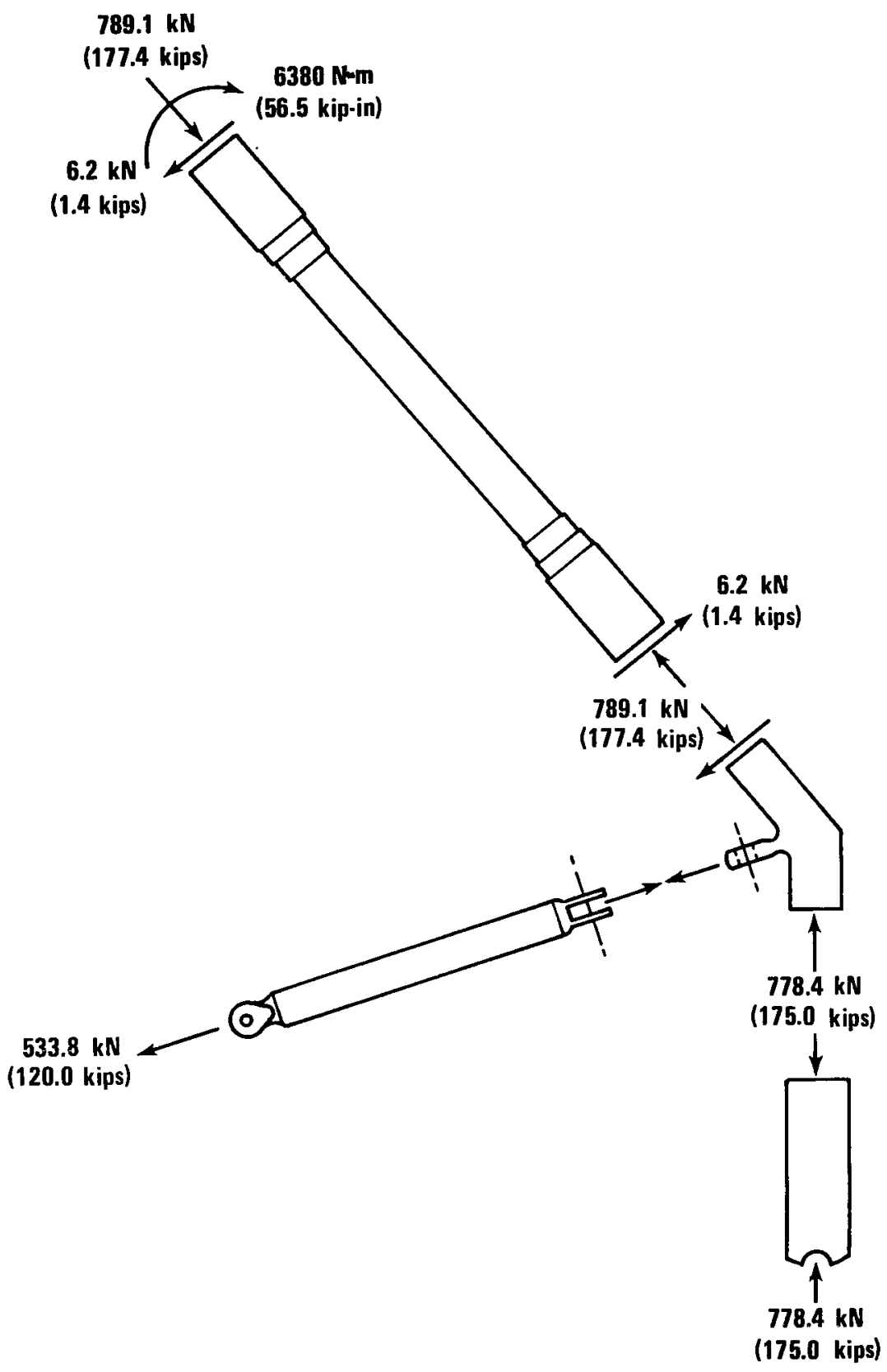

Figure 5.- Internal load distribution. 


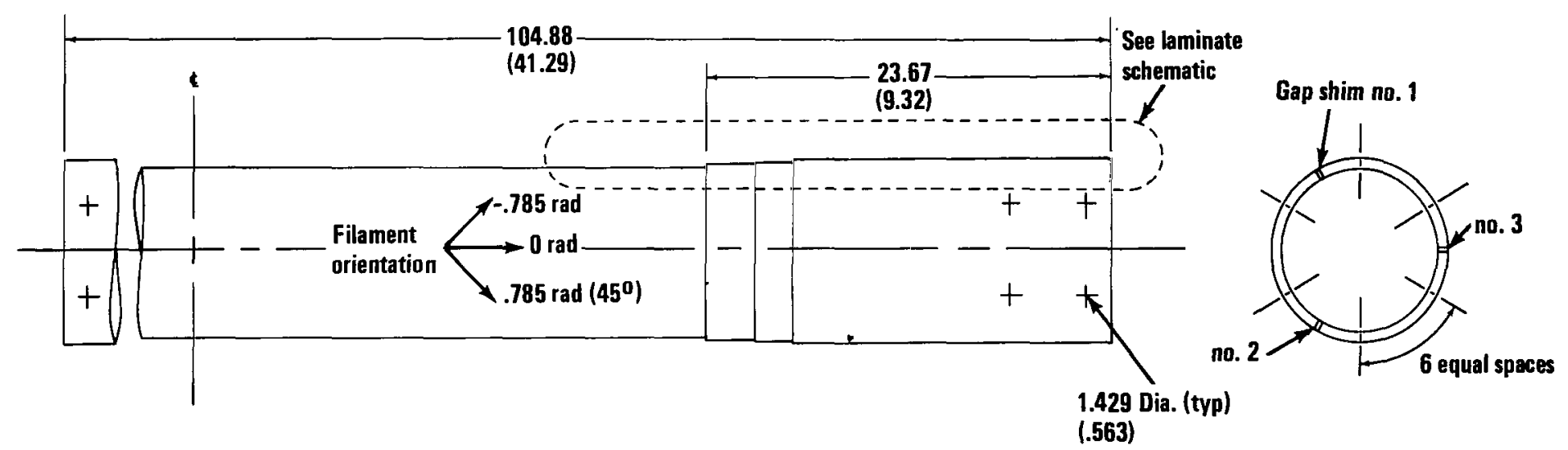

Note: All plies are at zero radians

unless otherwise noted.

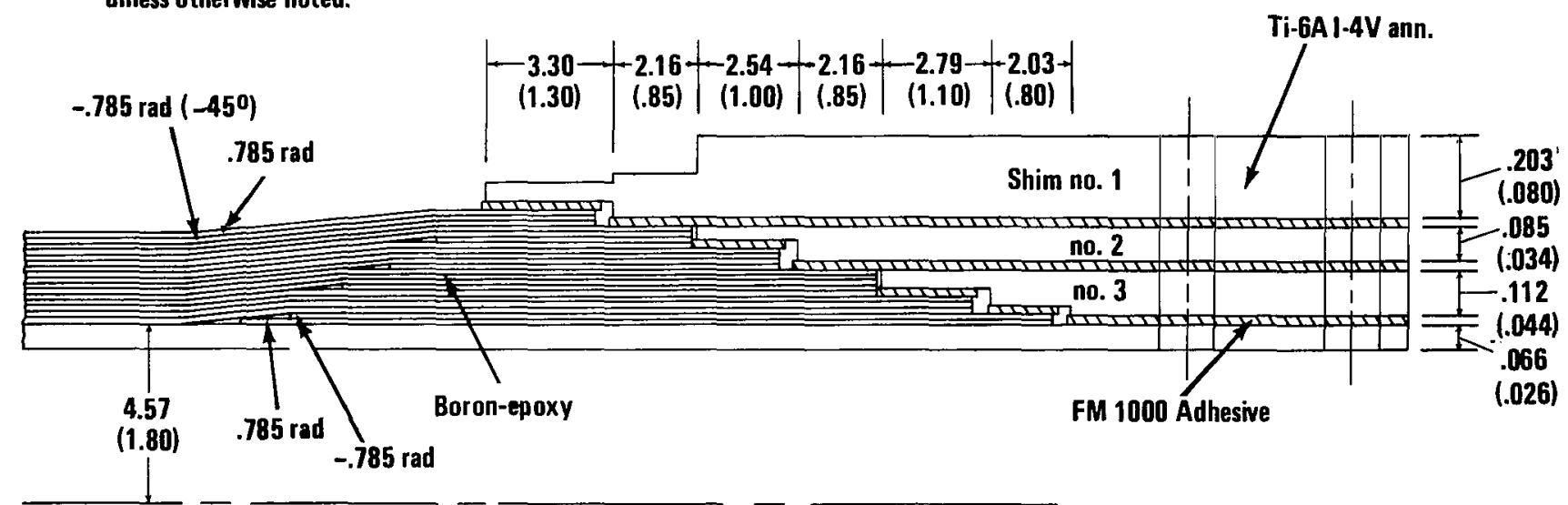

Laminate Schematic

(no scaie)

Figure 6.- Demonstration-truss compression member. Dimensions are given in centimeters (inches). 


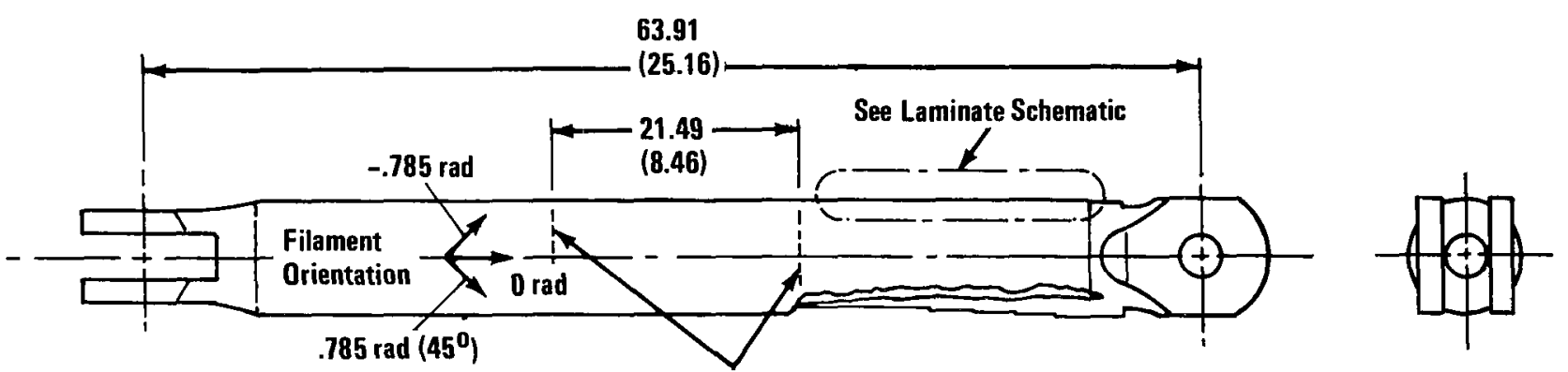

Butt Welds

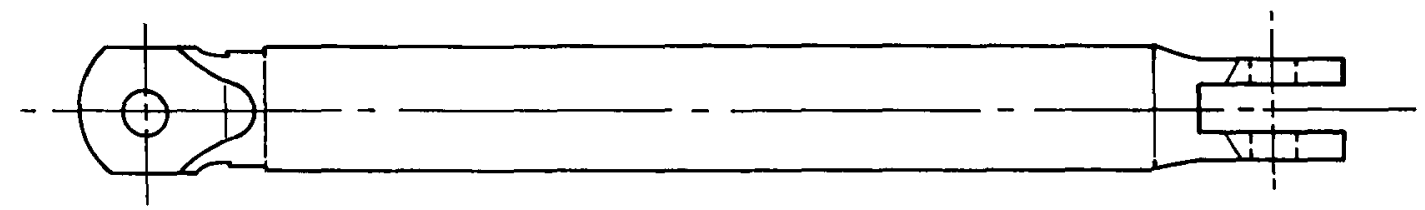

Note: All plies are at zero radians unless otherwise noted

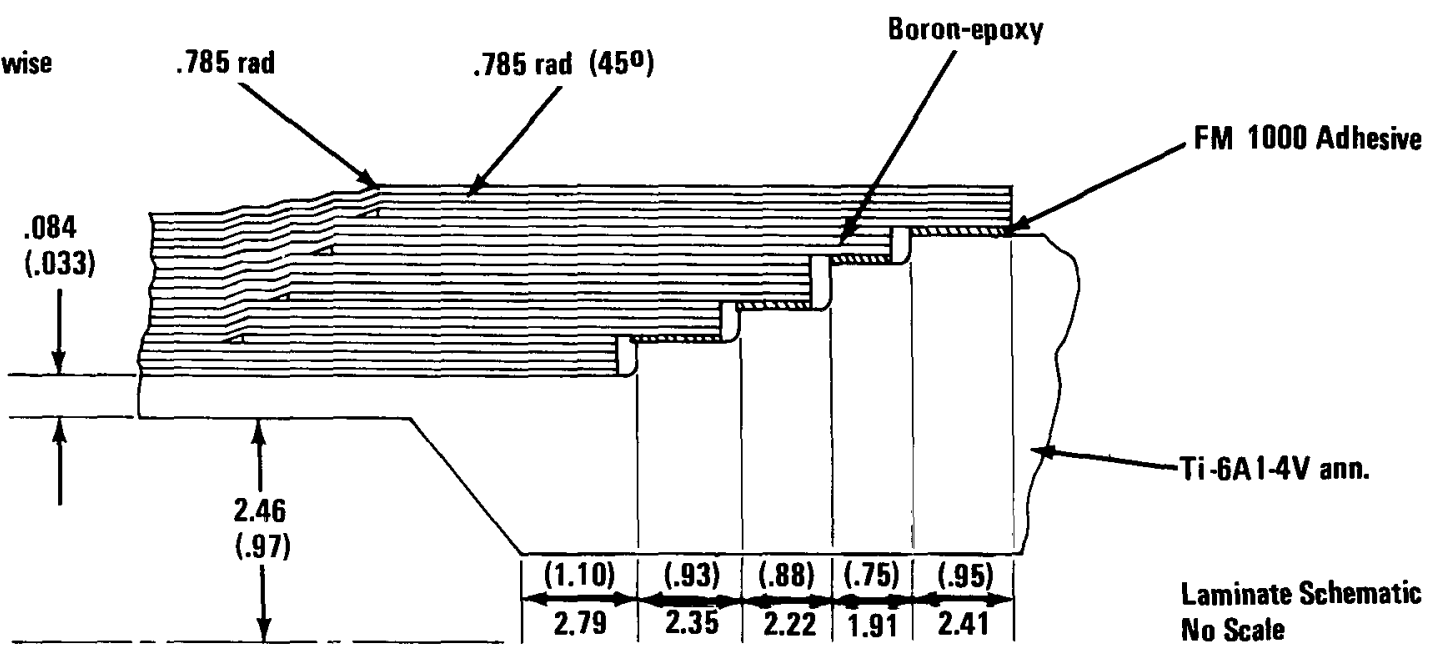

Figure 7.- Demonstration-truss tension member. Dimensions are given in centimeters (inches). 

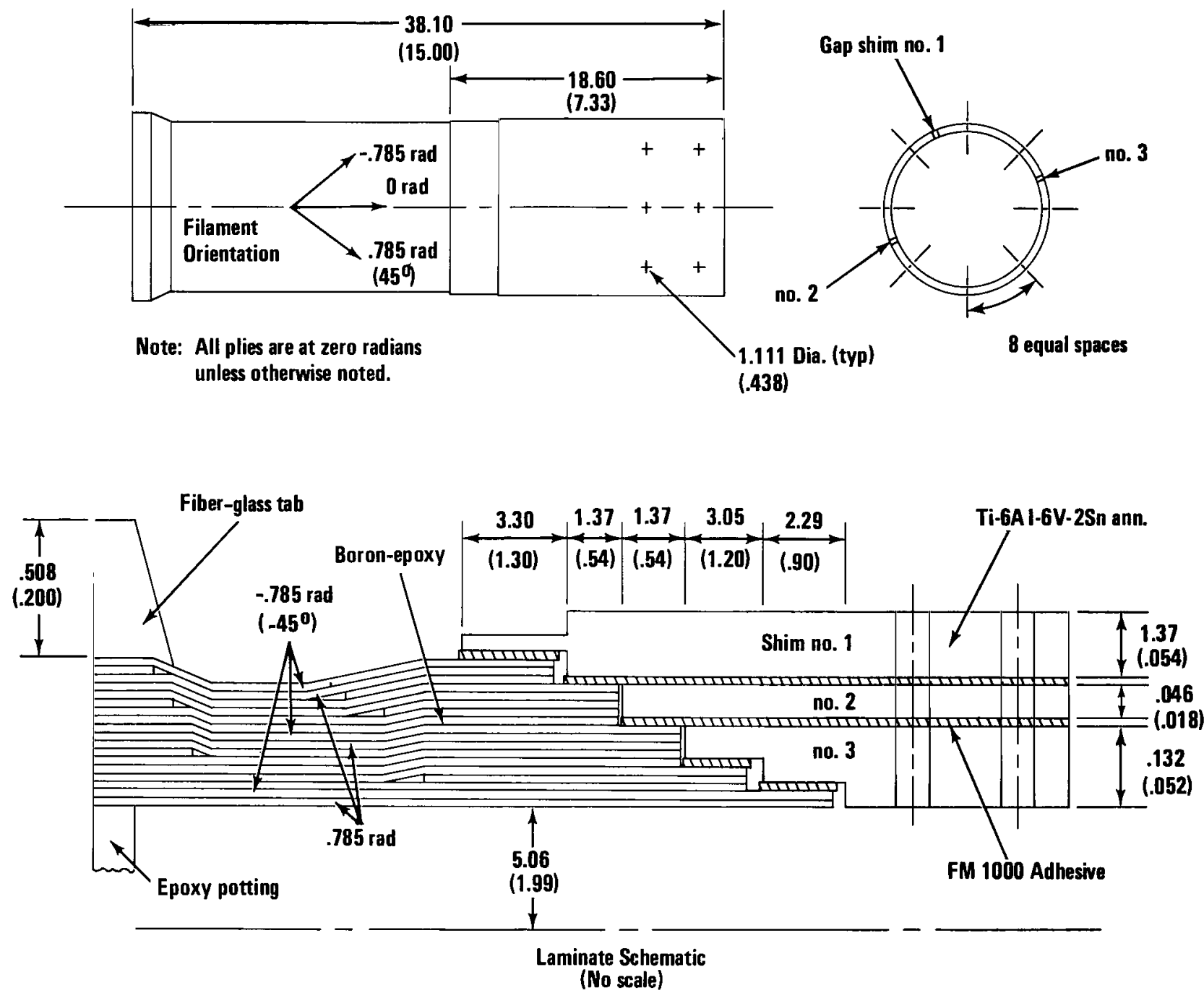

Figure 8.- Compression subelement specimen, all composite. Dimensions are given in centimeters (inches). 

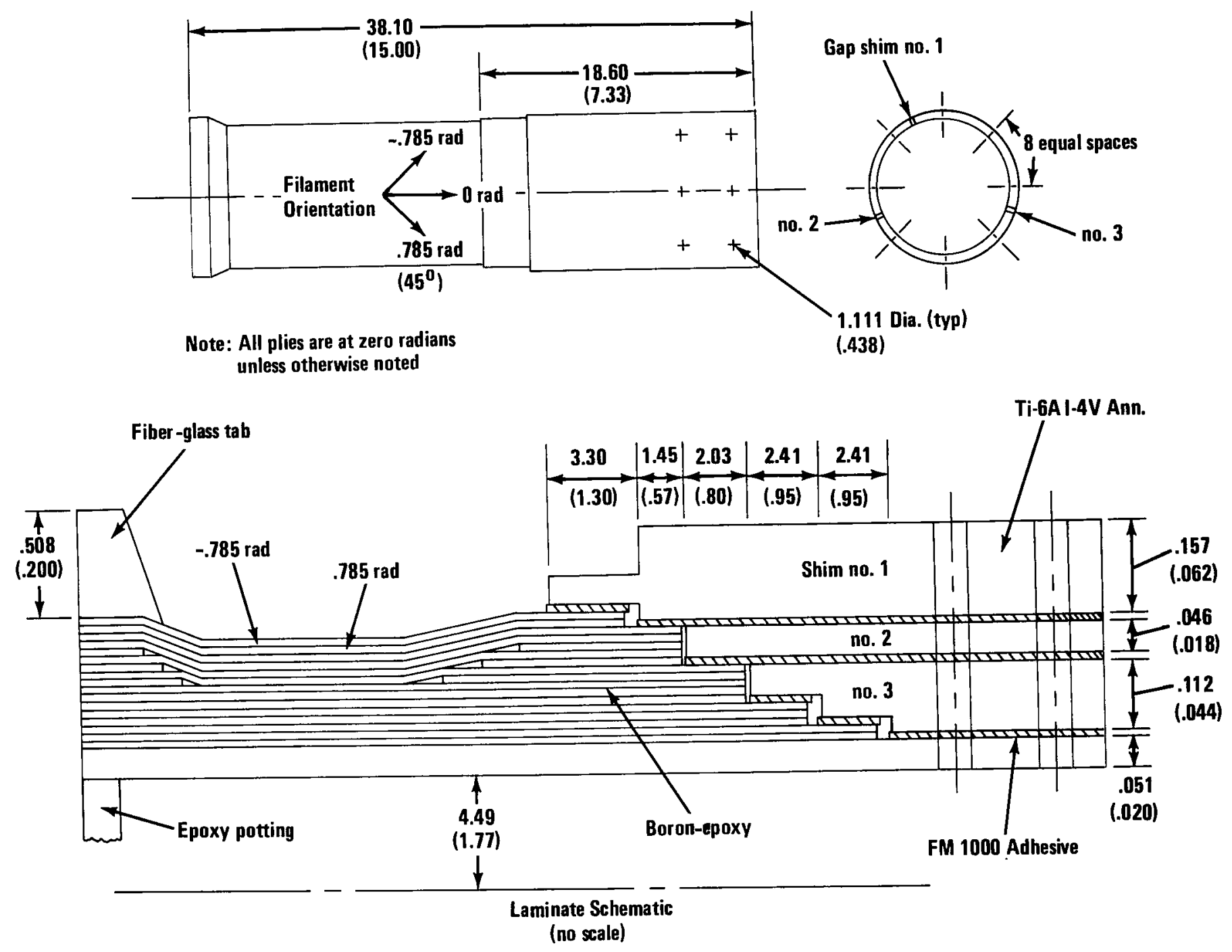

Figure 9.- Compression subelement specimen, composite-reinforced titanium.

Dimensions are given in centimeters (inches). 


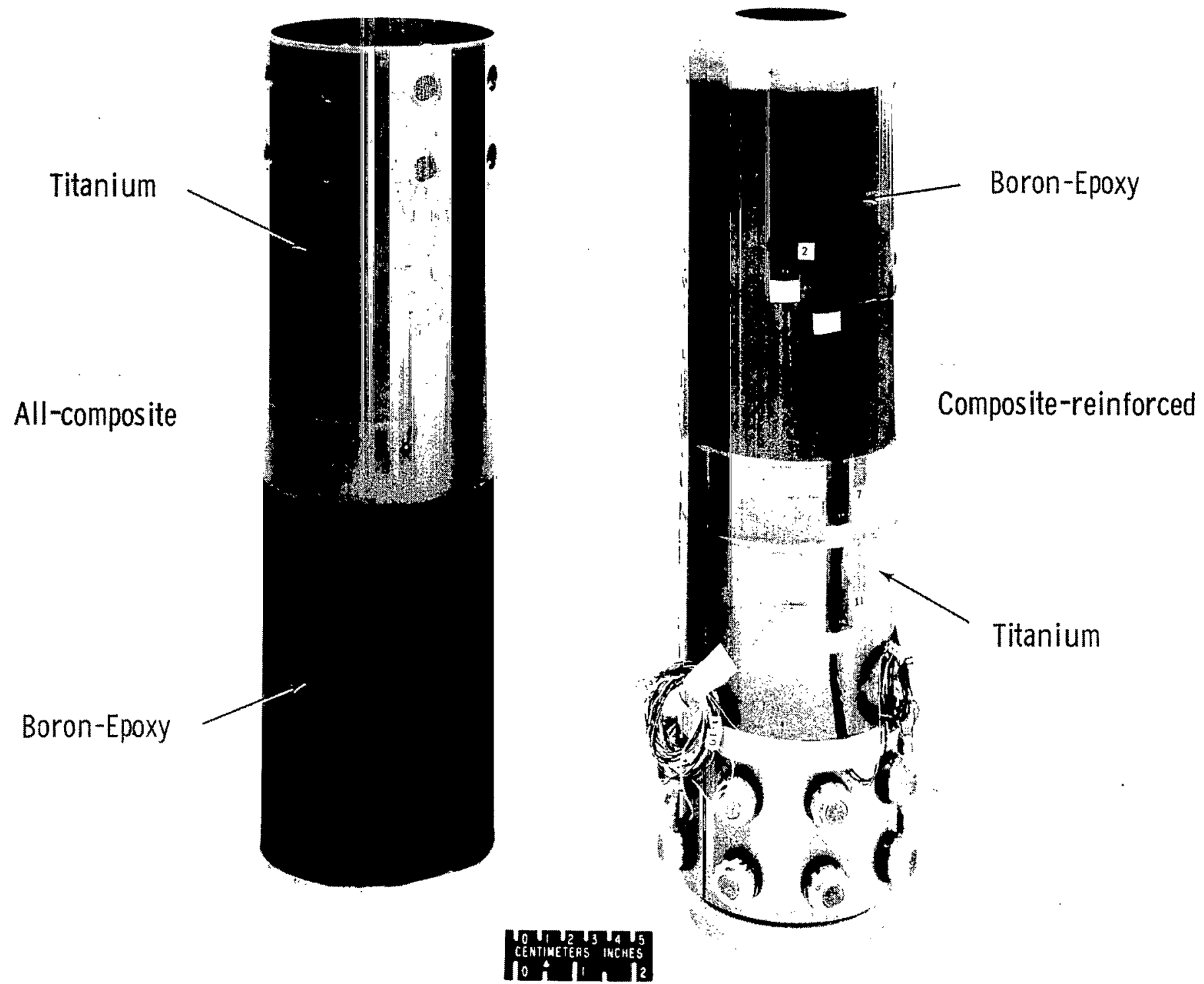




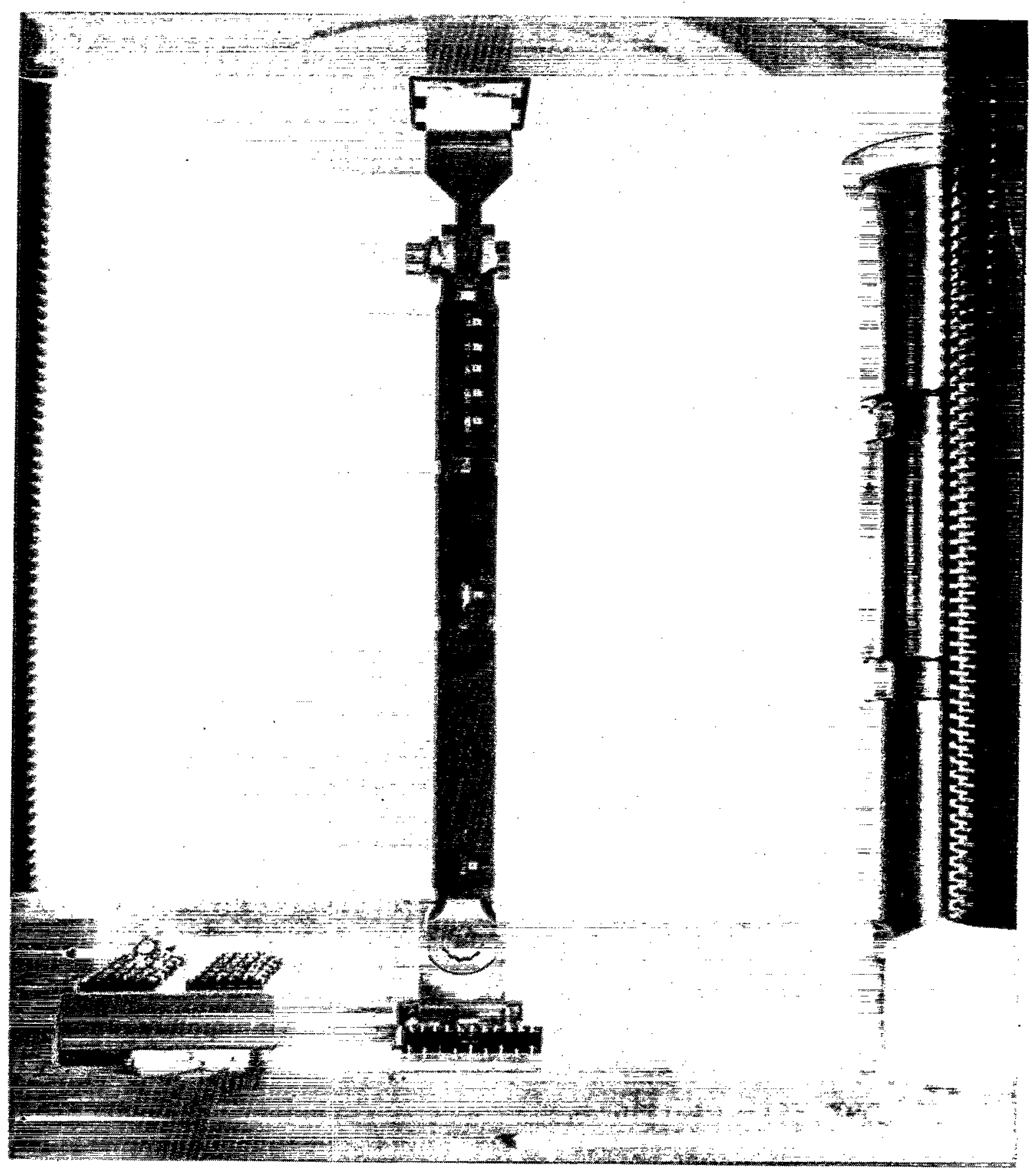

L-71-6426

Figure 11.- Tension test setup. 


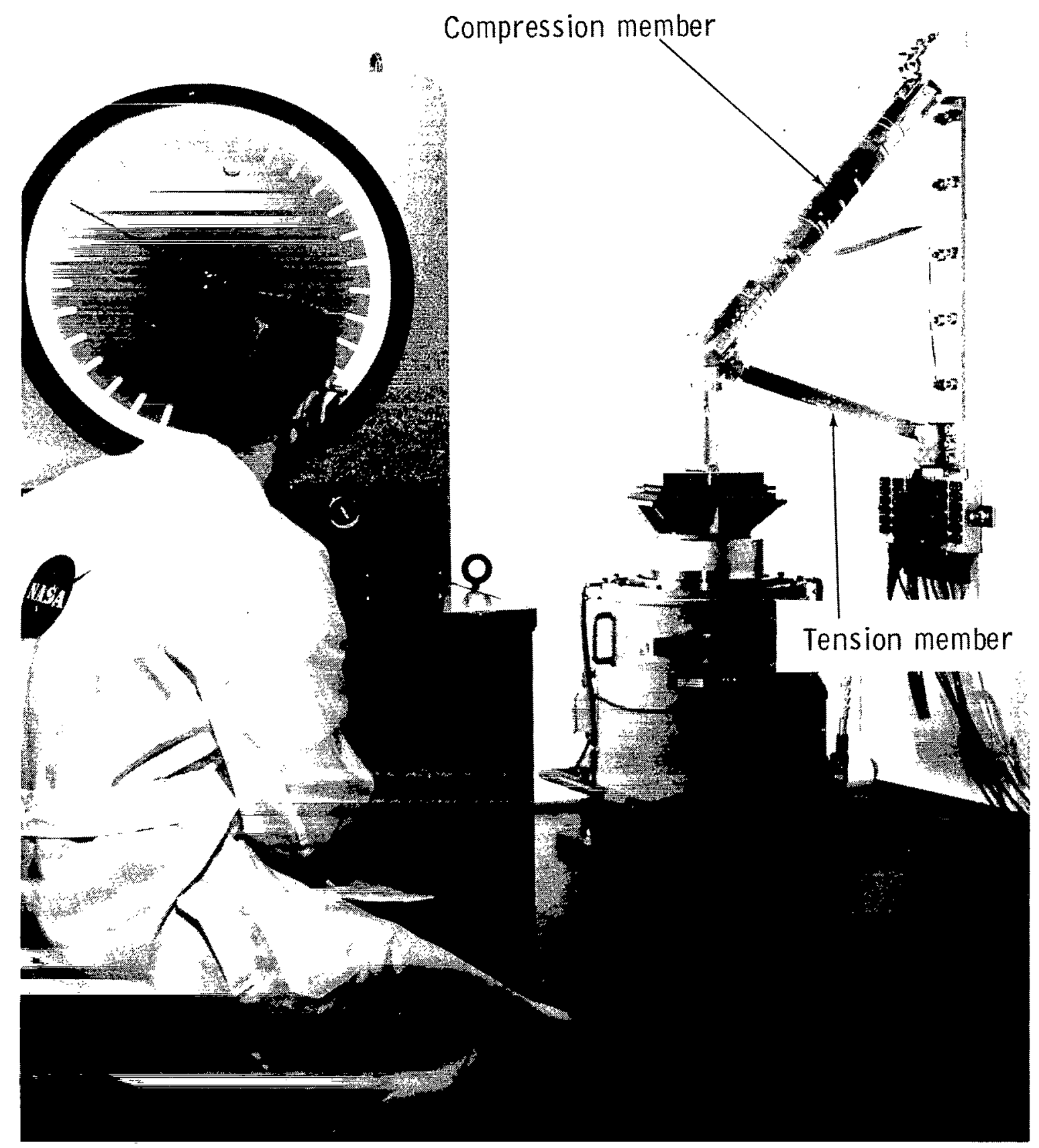

L-71-6057.1

Figure 12.- Demonstration-truss test setup. 


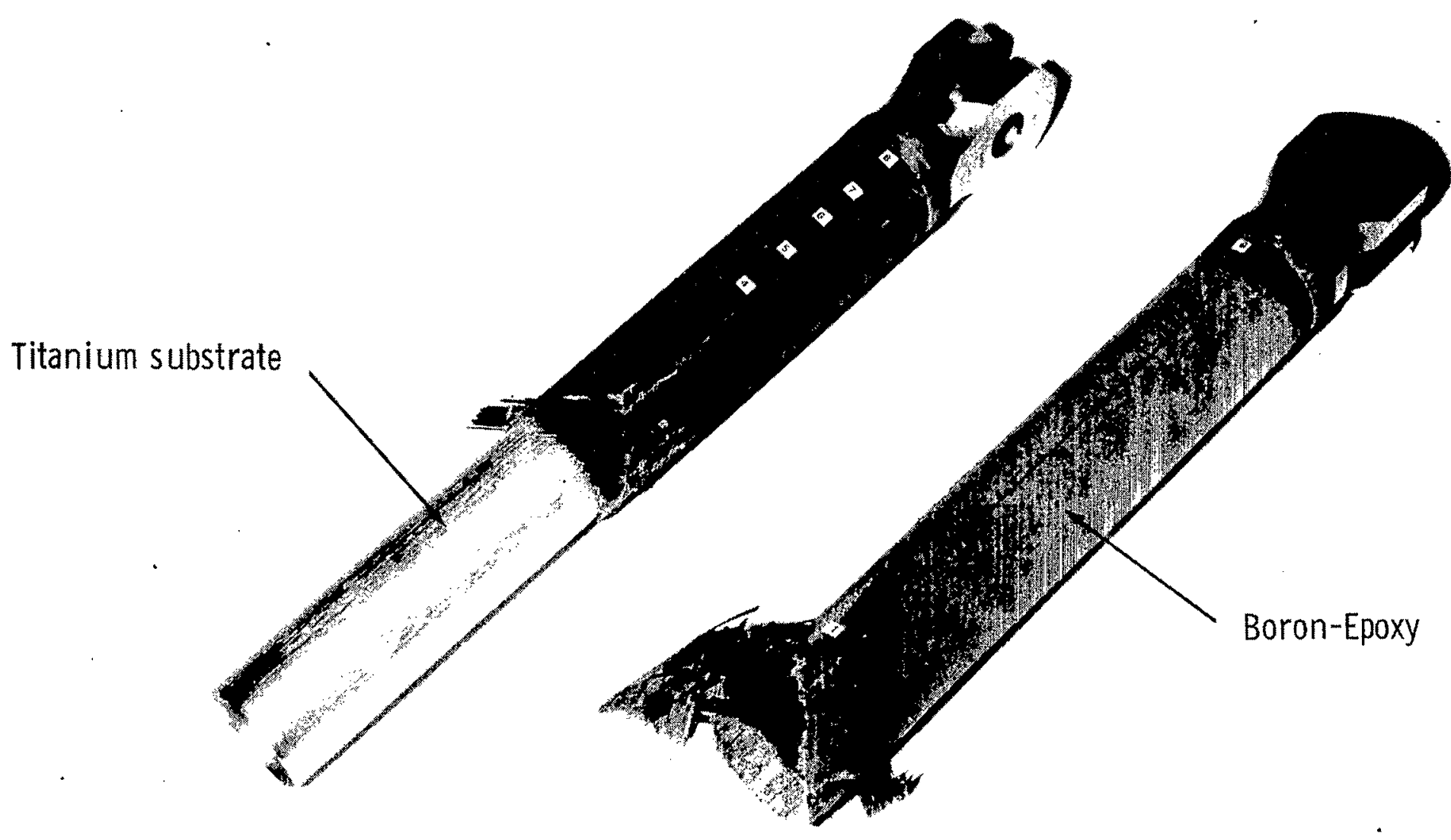

Figure 13.- Failure of tension element. 


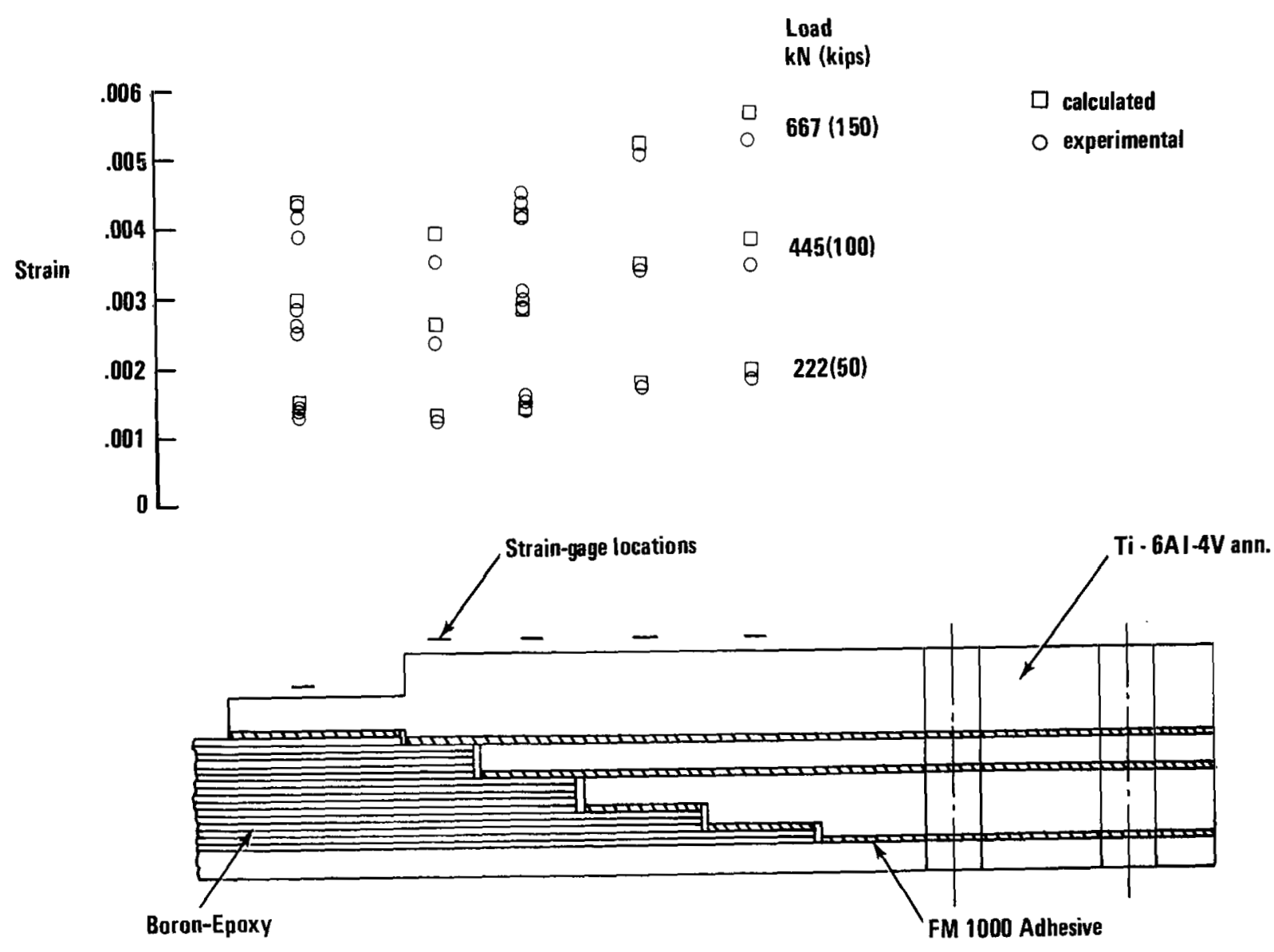

Figure 14.- Axial strain distribution in transition region of composite-reinforced compression subelement. 


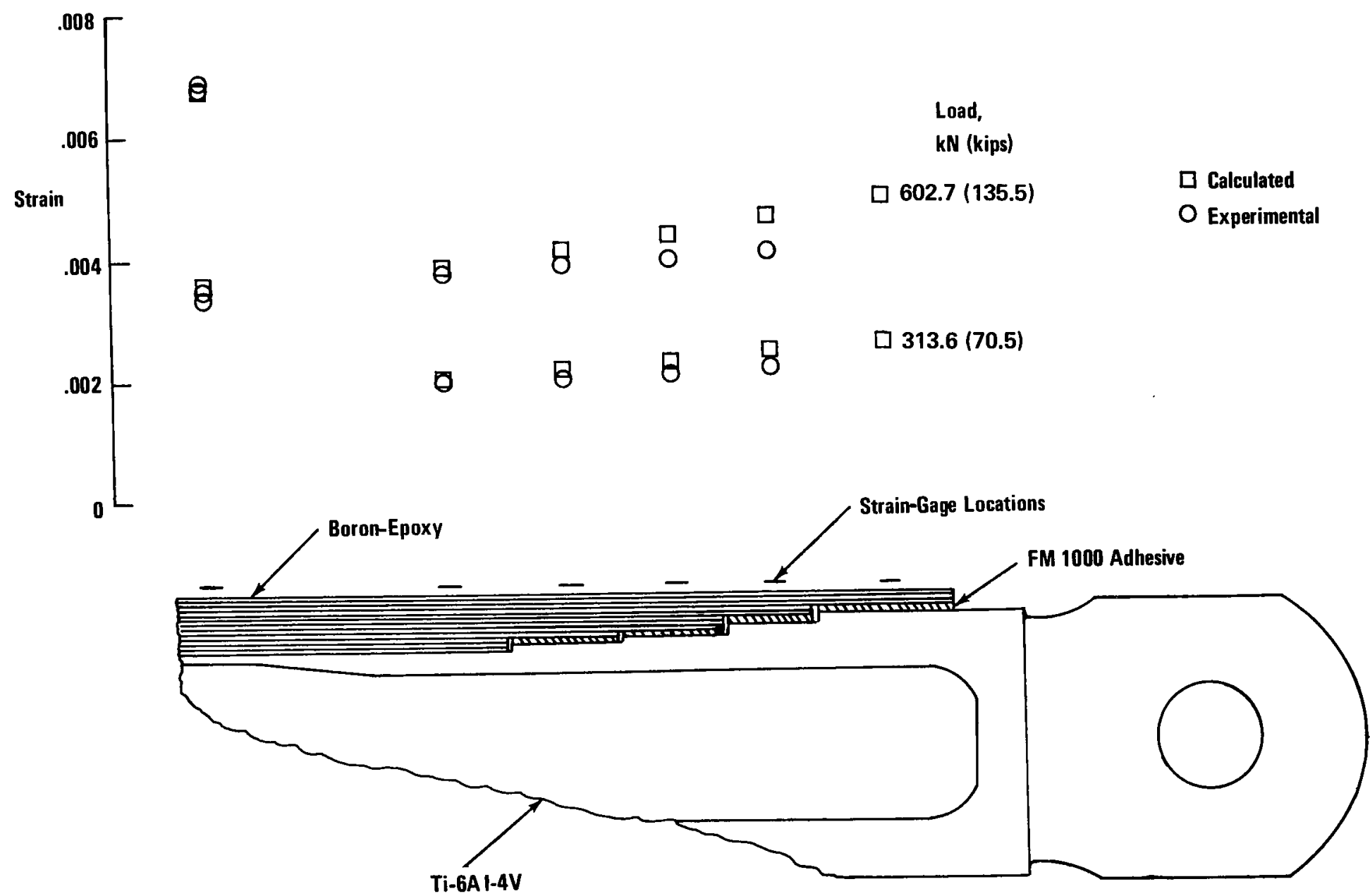

Figure 15.- Axial strain distribution in composite-reinforced tension element. 


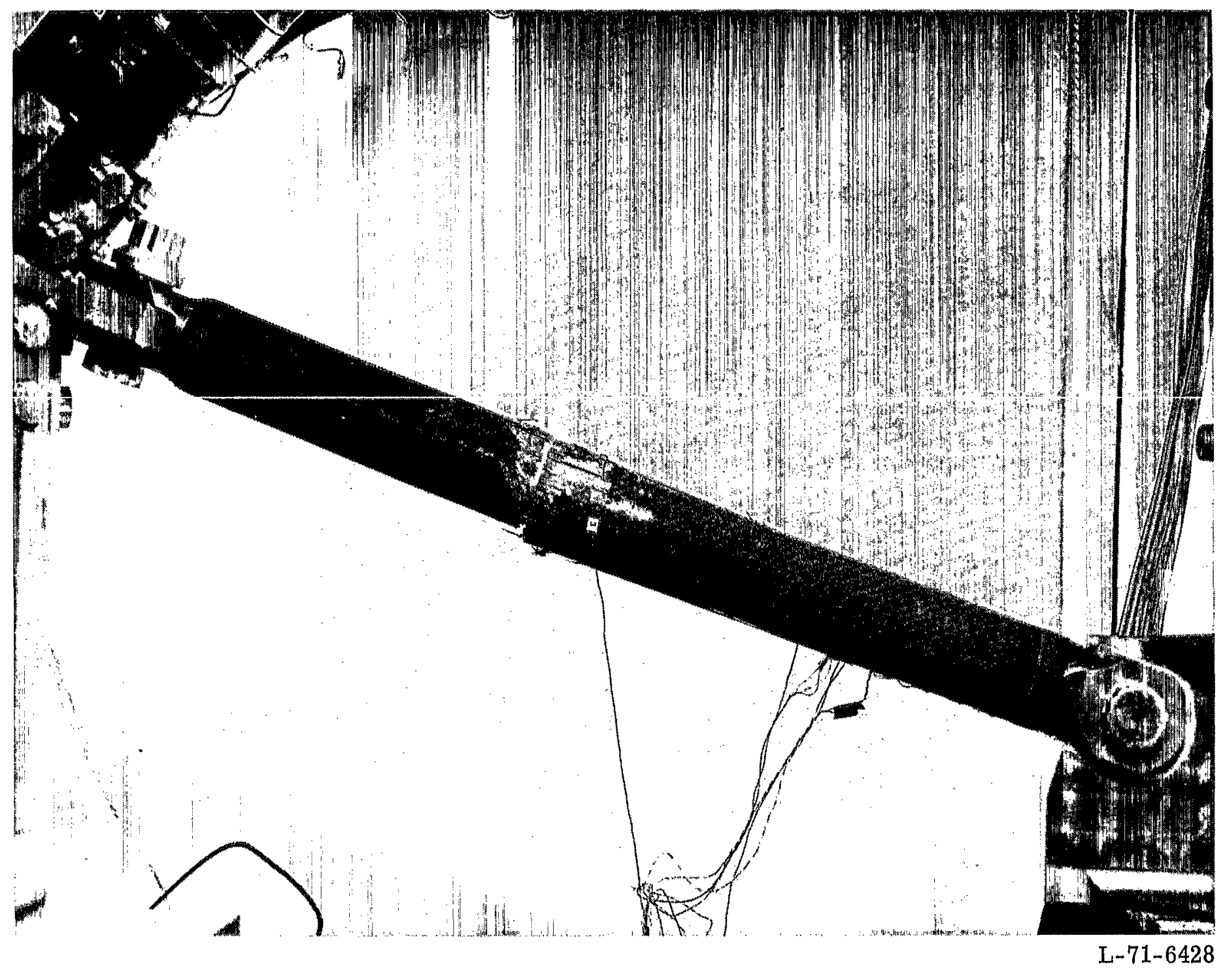

Figure 16.- Failure of demonstration truss. 


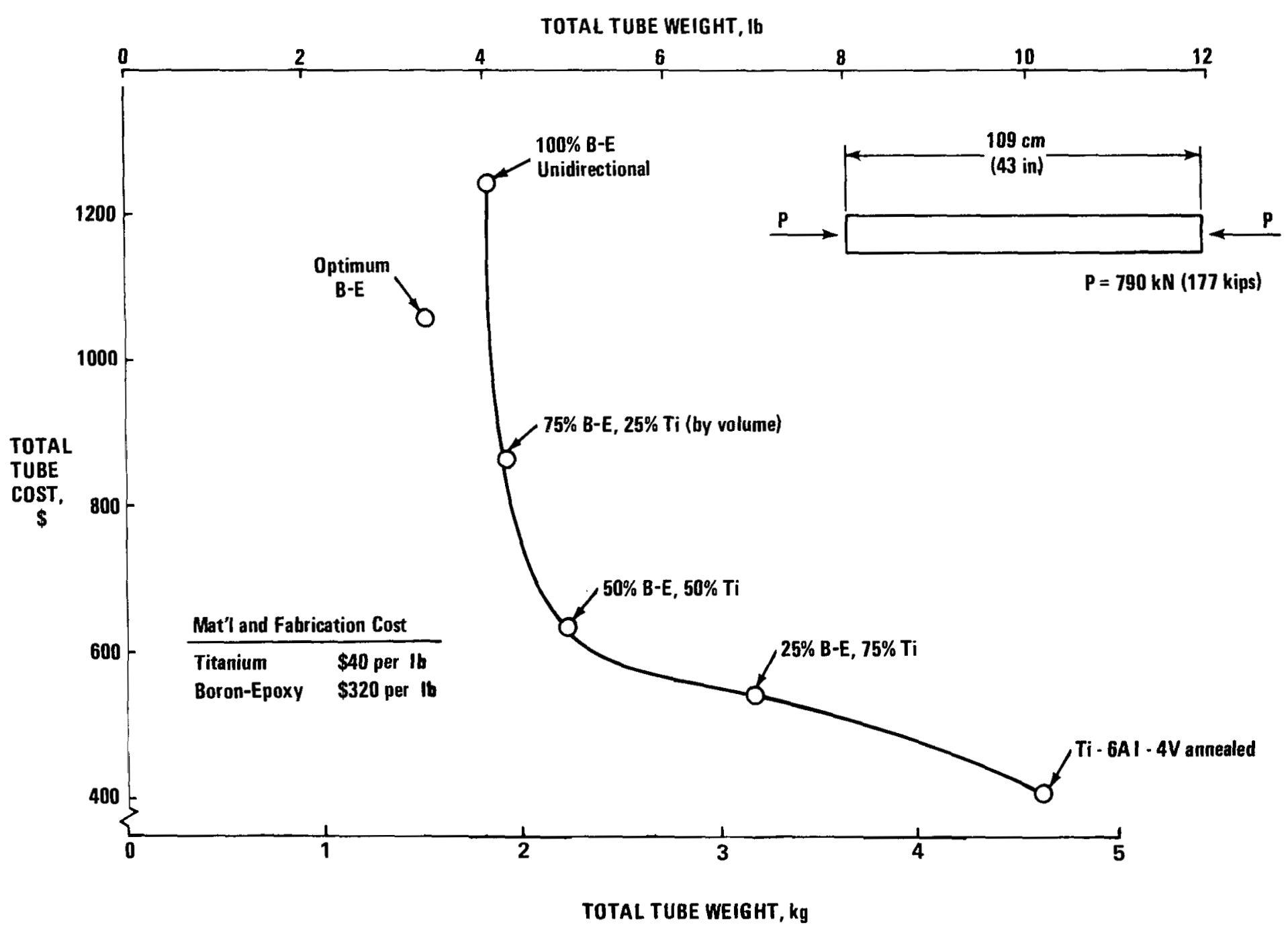

Figure 17.- Cost-weight comparison of composite-reinforced tubular columns. 


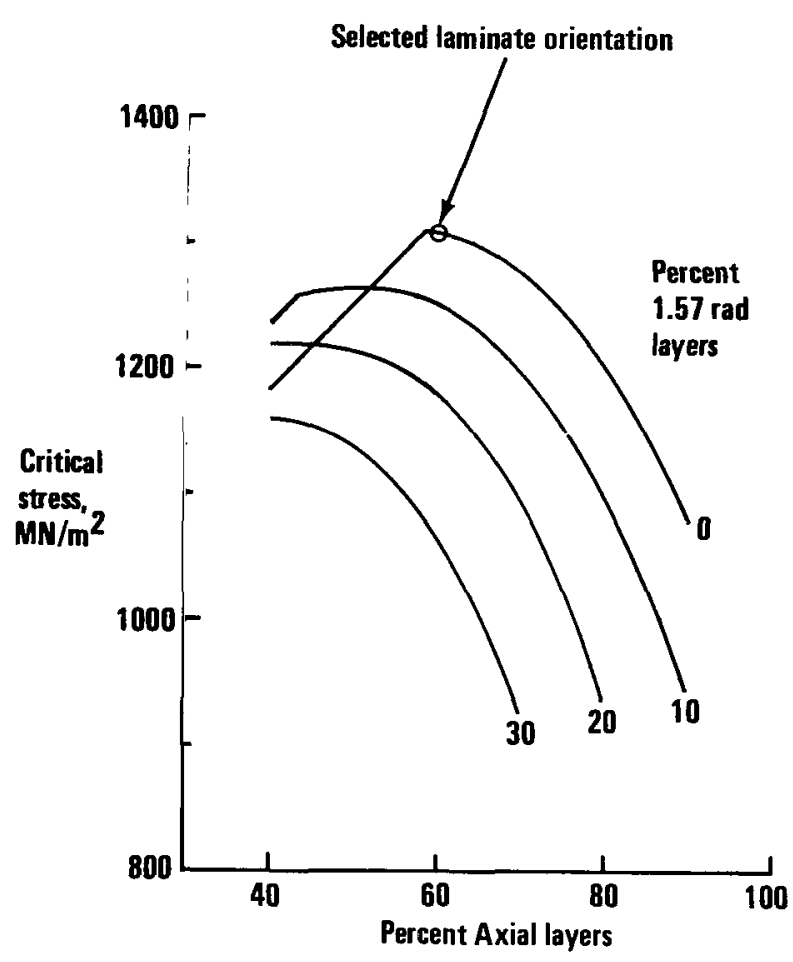

(a) Laminates with $0, \pm 0.785$, and $1.57 \mathrm{rad}$ $\left(0^{\circ}, \pm 45^{\circ}\right.$, and $\left.90^{\circ}\right)$ layers.

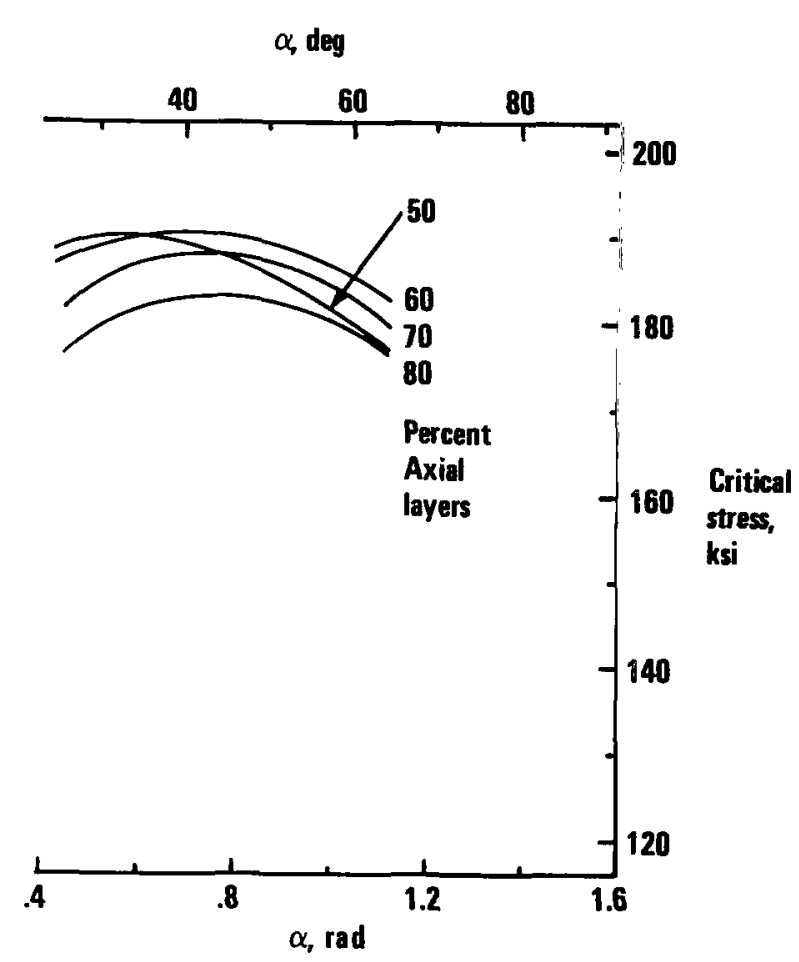

(b) Laminates with 0 and $\pm \alpha$ layers.

Figure 18.- Laminate orientation study. All-composite column. 

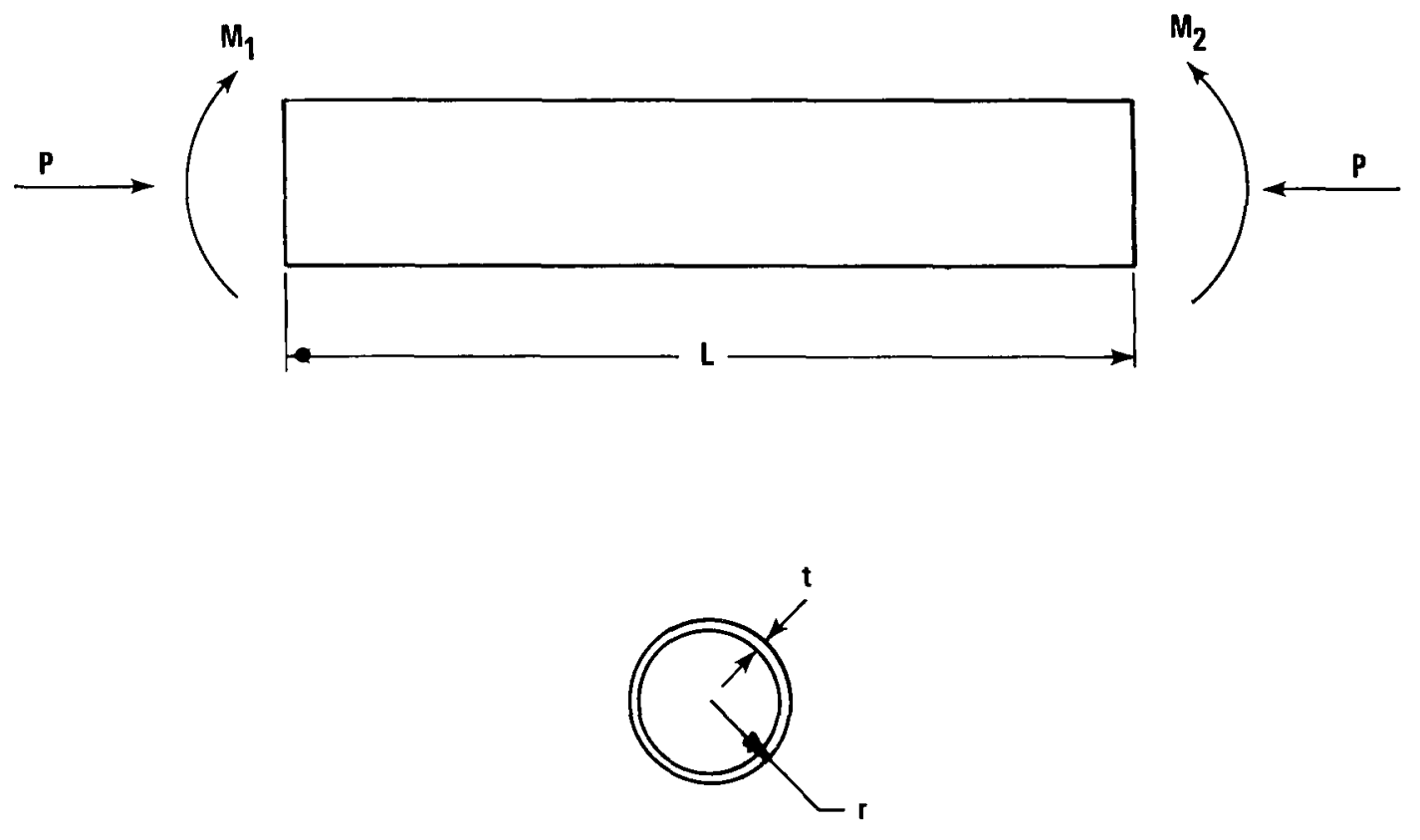

Cross section

Figure 19.- Beam column configuration and loading. Arrows indicate positive direction of moments. 


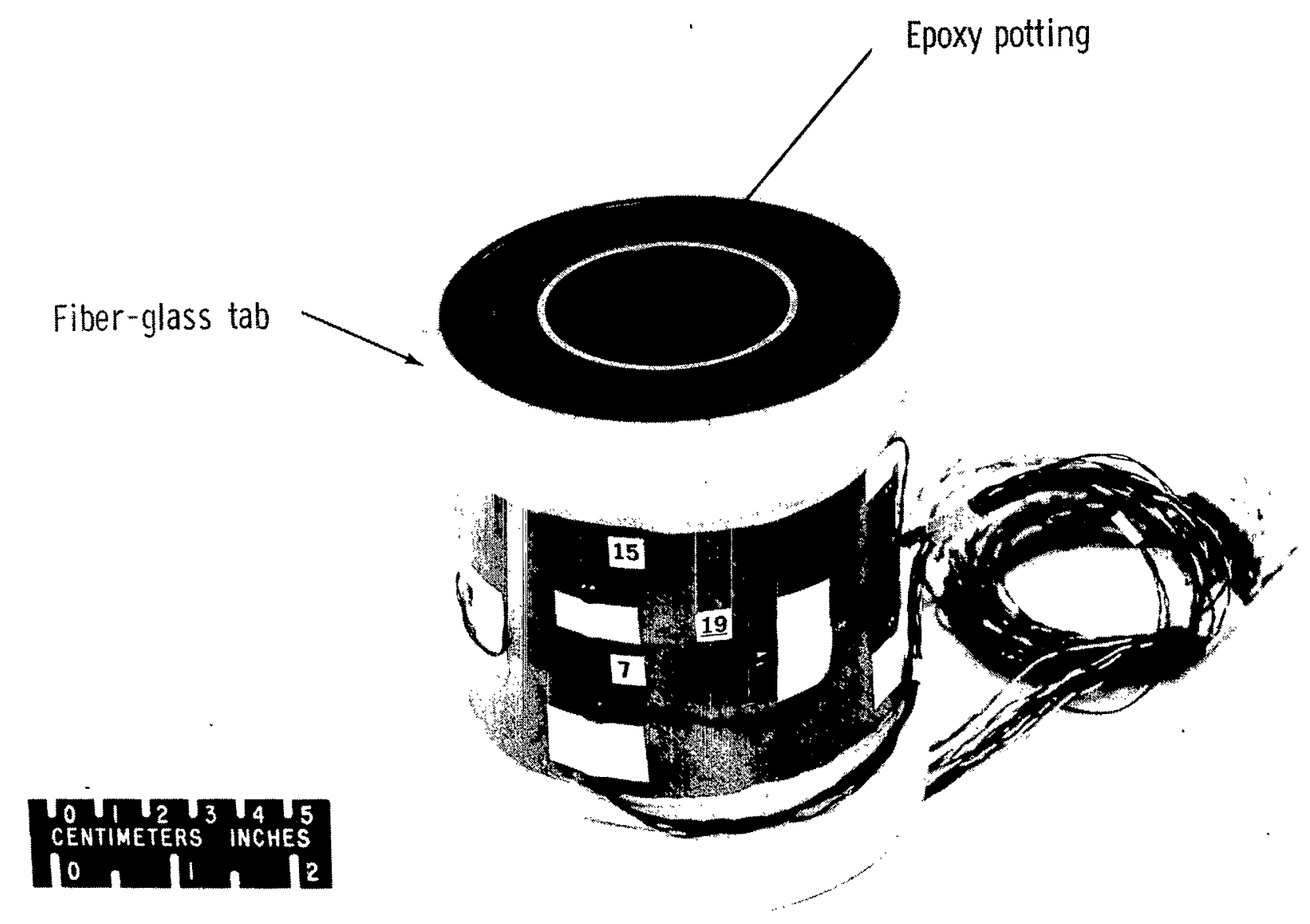

L-70-8825.1

Figure 20.- Local buckling specimen, composite reinforced, $10 \mathrm{~cm} \mathrm{(4} \mathrm{in.)} \mathrm{long.}$ 


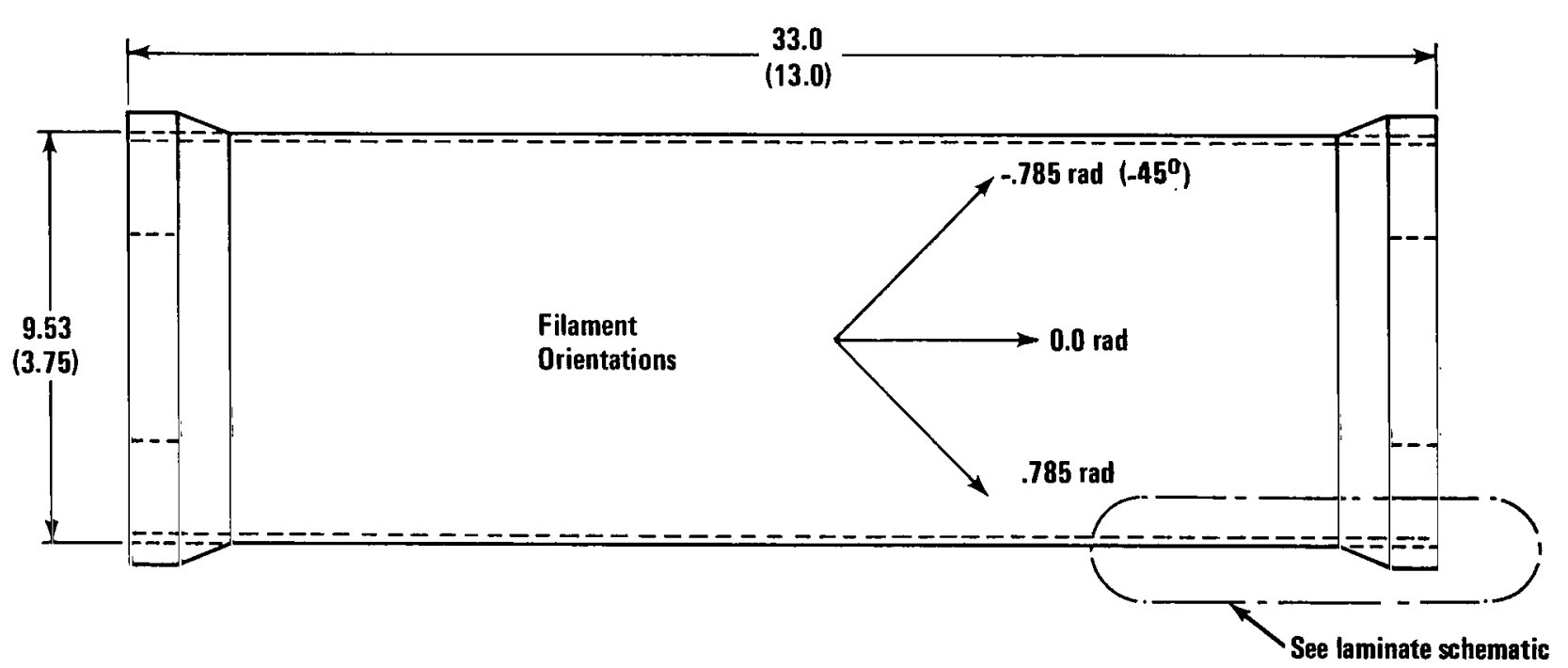

Note: All B-E plies oriented at zero radians except where noted.

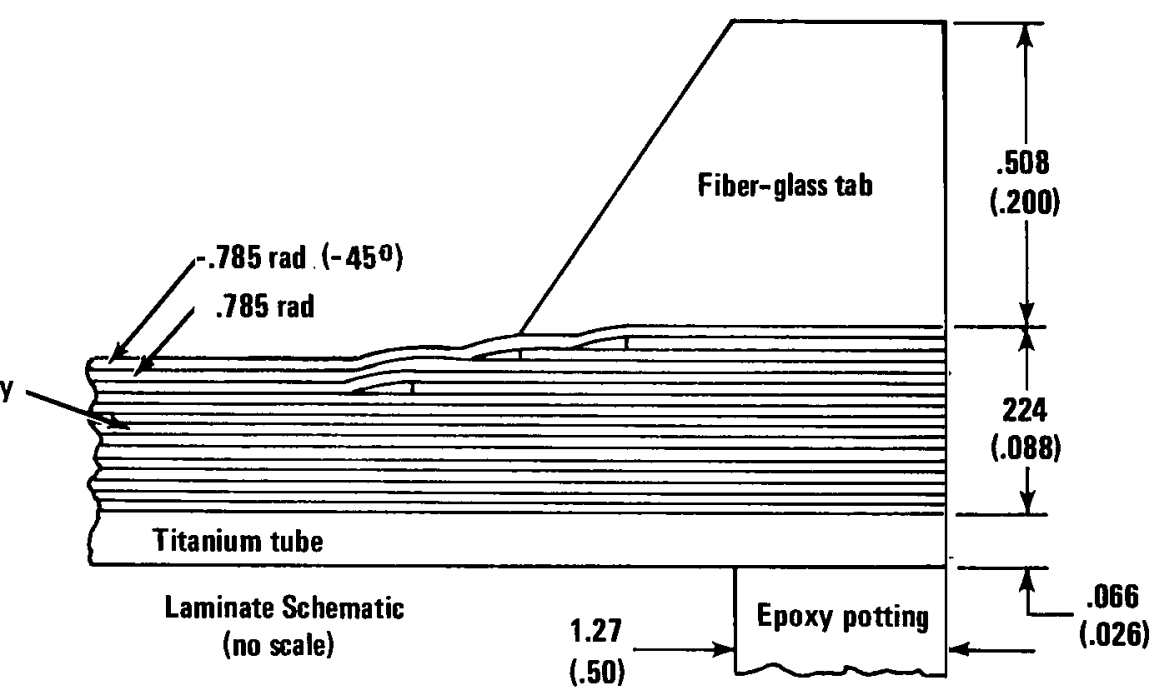

Figure 21.- Local buckling specimen, composite reinforced. Dimensions are given in centimeters (inches). 


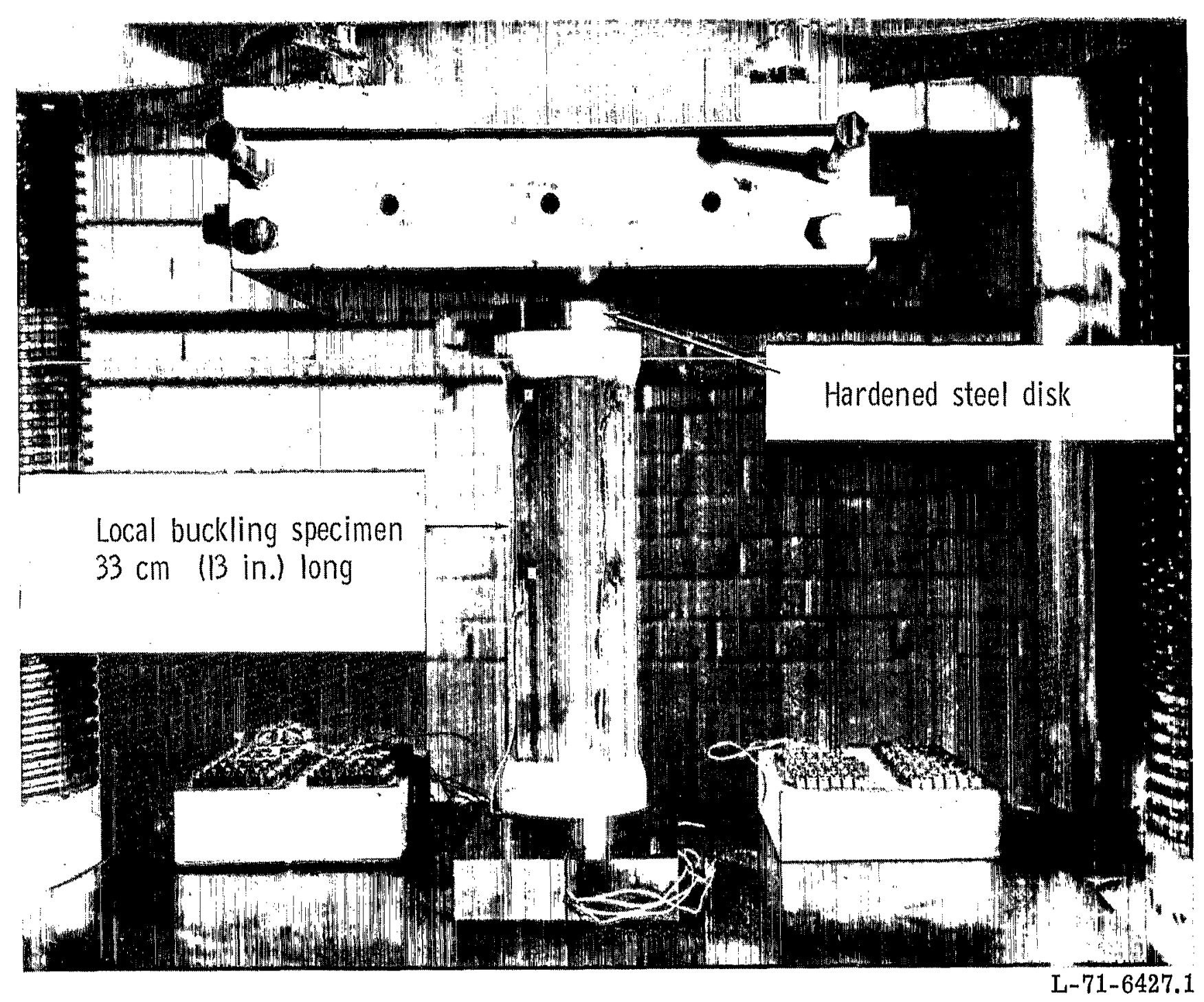

Figure 22.- Compression test setup. 


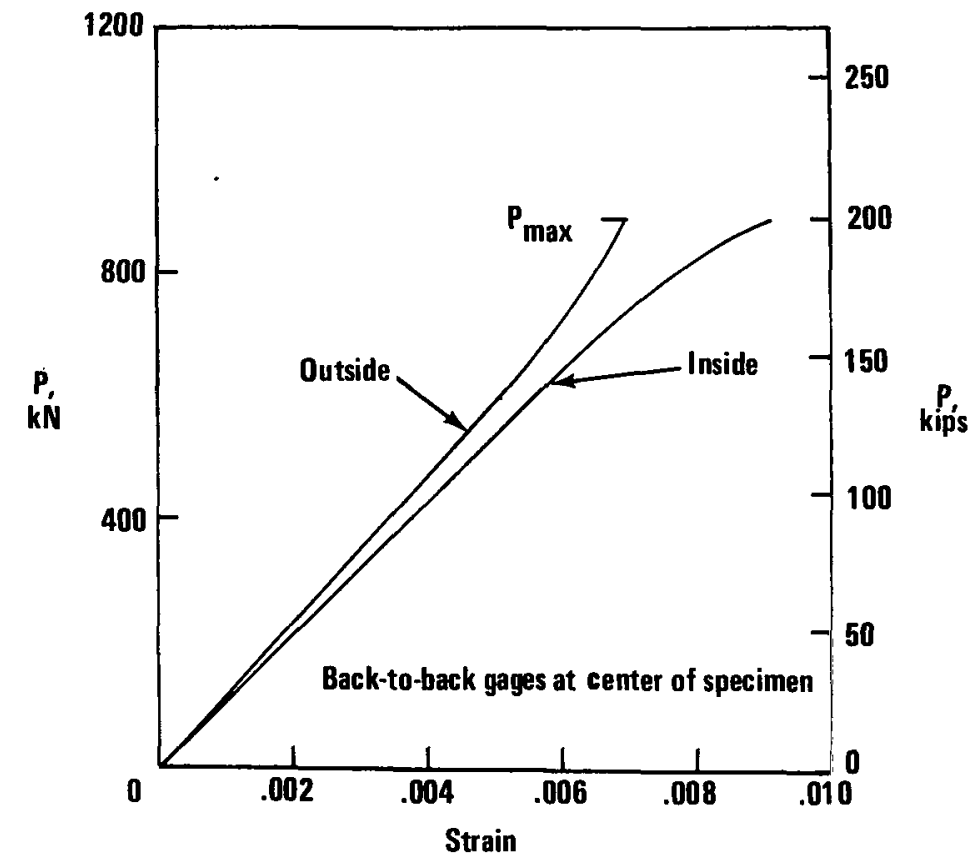

(a) 10-cm (4-in.) specimen.

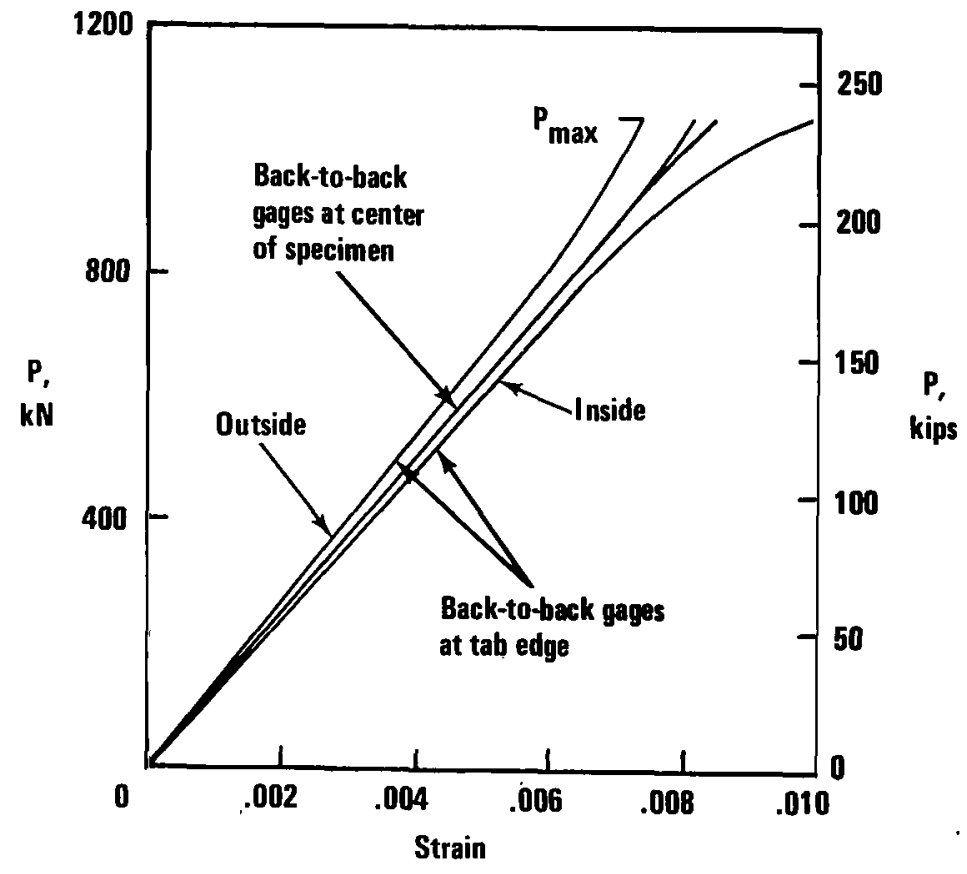

(b) 33-cm (13-in.) specimen.

Figure 23.- Load-strain data for boron-epoxy-reinforced titanium local buckling specimens. 

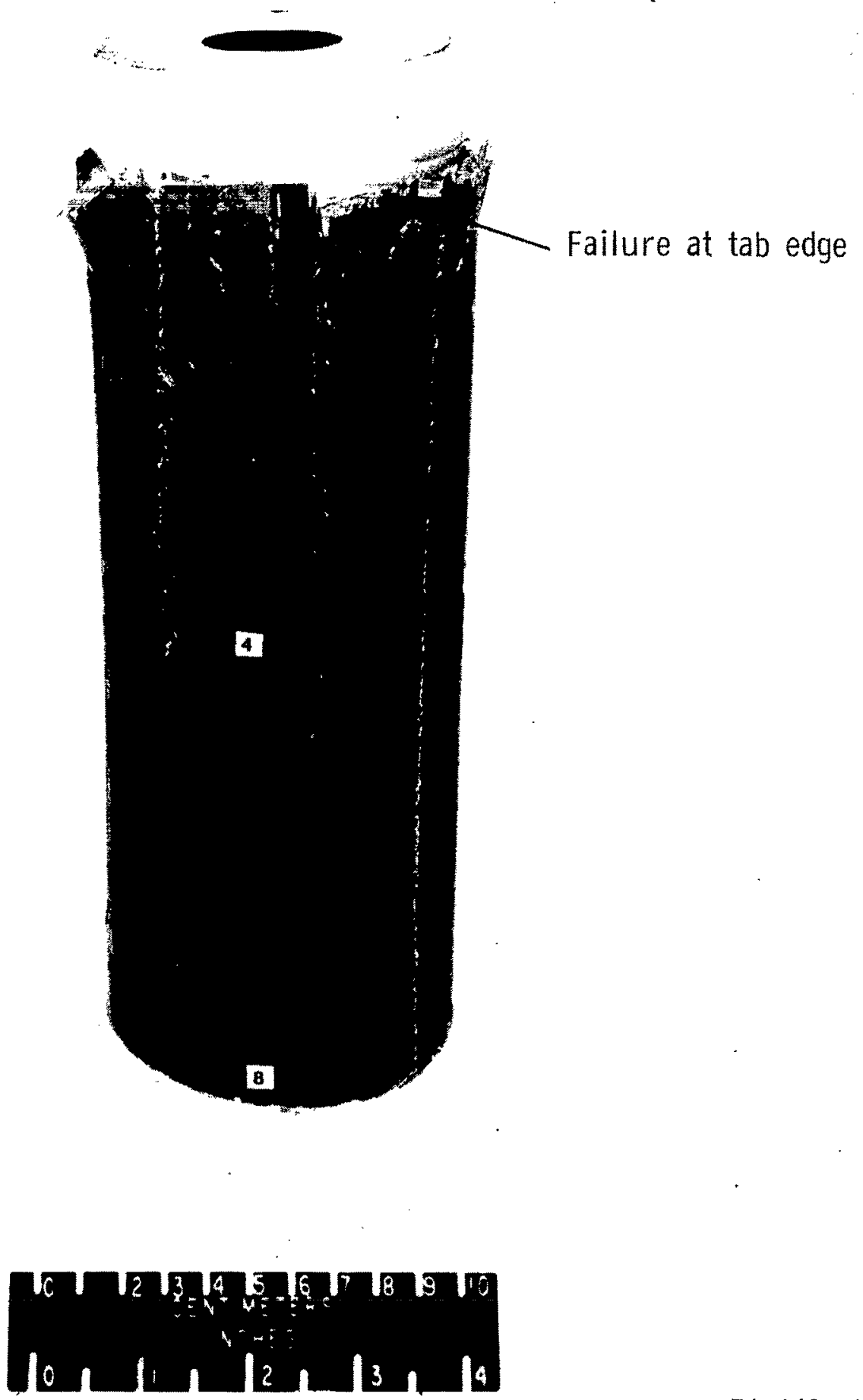

Figure 24.- Failure of local buckling specimen. 
"The aeronautical and space activities of the United States shall be conducted so as to contribute. . . to the expansion of buman knowledge of phenomena in the atmosphere and space. The Administration shall provide for the widest practicable and appropriate dissemination of information concerning its activities and the results thereof."

\section{NASA SCIENTIFIC AND TECHNICAL PUBLICATIONS}

TECHNICAL REPORTS: Scientific and technical information considered important, complete, and a lasting contribution to existing knowledge.

TECHNICAL NOTES: Information less broad in scope but nevertheless of importance as a contribution to existing knowledge.

\section{TECHNICAL MEMORANDUMS:}

Information receiving limited distribution because of preliminary data, security classification, or other reasons.

CONTRACTOR REPORTS: Scientific and technical information generated under a NASA contract or grant and considered an important contribution to existing knowledge.

\author{
TECHNICAL TRANSLATIONS: Information \\ published in a foreign language considered \\ to merit NASA distribution in English.
}

SPECIAL PUBLICATIONS: Information derived from or of value to NASA activities. Publications include conference proceedings, monographs, data compilations, handbooks, sourcebooks, and special bibliographies.

\section{TECHNOLOGY UTILIZATION}

PUBLICATIONS: Information on technology used by NASA that may be of particular interest in commercial and other non-aerospace applications. Publications include Tech Briefs, Technology Utilization Reports and

Technology Surveys.

Details on the availability of these publications may be obtained from:

SCIENTIFIC AND TECHNICAL, INFORMATION OFFICE NATIONAL AERONAUTICS AND SPACE ADMINISTRATION Washington, D.C. 20546 